UNIVERSIDADE DE SÃO PAULO

FACULDADE DE MEDICINA DE RIBEIRÃO PRETO

JUAN JAVIER MOREIRA MOREIRA

Estudo morfométrico do forame transverso

Ribeirão Preto

2019 
JUAN JAVIER MOREIRA MOREIRA

\title{
Estudo morfométrico do forame transverso
}

\author{
Versão Original
}

Dissertação apresentada à Faculdade de Medicina de Ribeirão Preto da Universidade de São Paulo para obtenção do título de Mestre em Ciências.

Orientador: Prof. Dr. Carlos Fernando P. S. Herrero

Ribeirão Preto

2019 
Autorizo a reprodução e divulgação total ou parcial deste trabalho, por qualquer meio convencional ou eletrônico, para fins de estudo e pesquisa, desde que citada a fonte.

FICHA CATALOGRÁFICA

MOREIRA, Juan Javier Moreira

Estudo morfométrico do forame transverso. Ribeirão Preto, 2019.

68 p. : il. ; $30 \mathrm{~cm}$.

Dissertação de Mestrado apresentada ao Programa de Pós-Graduação em Ciências da Saúde Aplicadas ao Aparelho Locomotor da Faculdade de Medicina de Ribeirão Preto/USP.

Orientador: Carlos Fernando Pereira da Silva Herrero. 


\section{FOLHA DE APROVAÇÃO}

Juan Javier Moreira Moreira

Estudo morfométrico do forame transverso.

Dissertação apresentada à Faculdade de Medicina de Ribeirão Preto da Universidade de São Paulo para obtenção do título de Mestre em Ciências.

Aprovado em:

\section{Banca Examinadora}

Prof. Dr.

Instituição:

Assinatura:

Prof. Dr.

Instituição:

Assinatura:

Prof. Dr.

Instituição:

Assinatura: 


\section{DEDICATÓRIA}

A Deus, sábio guia, pela presença constante nos momentos difíceis da minha existência. Aos meus pais, Juan e Edith, pela vida e pelo apoio incondicional.

À minha esposa Fabiana, fonte de inspiração, pelo amor, paciência e suporte.

Aos meus filhos, Camila, Lucas e Julia que traçam a direção e a alegria na minha vida. Ao meu irmão Gary, pelas ideias e conselhos.

Aos meus sogros Rubens e Conceição pelo apoio sem trégua. 


\section{AGRADECIMENTOS}

Ao Prof. Dr. Carlos Fernando Pereira da Silva Herrero, brilhante profissional e amigo dotado de retidão, pelas orientações desde o início da minha formação na especialidade. Mas, principalmente pela paciência e carinho, elementos essenciais de um verdadeiro professor.

Ao Prof. Dr. Andrés Edgard Rodriguez Fuentes, pelo acolhimento e ensinamentos, desde que pisei em terra brasileira, e por ter me permitido estar do seu lado aprendendo detalhes da sua experiência.

Aos professores e funcionários da pós-graduação do programa de ciências da saúde aplicadas ao aparelho locomotor da FMRP-USP, pela dedicação e ensinamentos transmitidos.

Aos meus amigos e aos meus residentes do serviço de Ortopedia do Hospital da Santa Casa de Ribeirão Preto, pela motivação para continuar neste caminho do ensino. 
"You'll never change your life until you change something you do daily.

The secret of your success is found in your daily routine"

John Calvin Maxwell 


\section{RESUMO}

MOREIRA, J. J. M. Estudo morfométrico do forame transverso. 2019. - f. 68 Dissertação (Mestrado) - Faculdade de Medicina de Ribeirão Preto, Universidade de São Paulo, Ribeirão Preto, SP, 2019.

O conhecimento da anatomia do forame transverso e a relação que possui com as estruturas vasculonervosas é importante quando se realiza procedimentos cirúrgicos na coluna cervical. Uma vez que, estudos morfométricos realizados em diferentes raças e etnias apresentam diferenças anatômicas é essencial que dados obtidos na literatura sejam utilizados com cautela, já que podem não ser aplicados universalmente. O objetivo deste trabalho foi analisar as características anatômicas do FT da coluna cervical baixa (C3-C7) e suas variações por meio de imagens tomográficas em uma amostra da população brasileira. Dois observadores independentes realizaram medidas lineares dos diâmetros anteroposterior (DAP) e lateral (DL) e a área (AF) em um total de 600 FTs da coluna cervical baixa de 60 indivíduos (30 do gênero feminino e 30 do masculino) com idade média de $43 \pm 18$. Os valores das medidas foram comparados entre os gêneros, entre os lados e entre diferentes grupos etários (18 a 40 anos; 41 a 60 anos; acima de 60 anos). Os menores DAP, DL e AF médio foram encontrados no nível C7 sem diferença entre os gêneros. Por outro lado, o maior DAP médio foi evidenciado em C6 e o maior DL médio foi evidenciado em C3 sem diferença entre os gêneros. Já os maiores valores médios da AF foram encontrados no nível vertebral cervical de $\mathrm{C} 3$ no grupo do gênero feminino e de C6 no grupo do gênero masculino. Os valores médios de DAP, DL e AF foram maiores no lado esquerdo quando comparado ao lado direito em todos os níveis. Notou-se uma tendência ao aumento dos valores médios da AF conforme o avanço da faixa etária. Quanto às variações anatômicas dos forames transversos, 57 indivíduos (95\%) do total da amostra apresentaram pelo menos uma alteração morfológica e 25 indivíduos (42\%) mais de três. A assimetria foi a variação mais frequentemente encontrada (35 indivíduos $=58,3 \%$ ), seguida pela duplicação de forame (32 indivíduos $=53,3 \%$ ), a formação em sulco ( 25 indivíduos $=$ $41,7 \%$ ), a hipoplasia de forame (22 indivíduos $=36,7 \%$ ), a agenesia de forame ( 5 indivíduos $=$ $8,3 \%$ ), o forame incompleto ( 3 indivíduos $=5 \%$ ) e finalmente a costela cervical em 1 indivíduo $(1,7 \%)$. Foram determinadas as características morfométricas dos FTs em imagens tomográficas e observou-se variações que justificam seu estudo prévio a procedimentos cirúrgicos que envolvem a coluna cervical.

Palavras-chave: Variação anatômica. Vértebras cervicais. Forame transverso. Costela cervical. Tomografia. 


\begin{abstract}
MOREIRA, J. J. M. Morphometric study of the transverse foramen. 2019. - f. 68 Dissertation - Ribeirão Preto Medical School - USP, 2019.

The knowledge of the transverse foramen anatomy and its relation to the neurovascular structures is essential while performing the surgical procedures on the cervical spine. The data on the literature should be used with caution, since they can not be applied universally because morphometric studies performed in different races and ethnicities show anatomical differences. The aim of this study was to analyze the characteristics of the transverse foramen anatomy of the lower cervical spine (C3-C7) and its anatomic variations by means of tomographic images in a Brazilian population sample. Two independent observers performed linear measurements of anteroposterior (APD) and lateral (LD) and area (FA) diameters for a total of 600 transverse foramens of the lower cervical spine of 60 individuals (30 females and 30 males) with a mean age $43 \pm 18$. The data were compared between genders, sides and between the different age groups (18 to 40 years, 41 to 60 years, over the 60 years). The lowest average values of the APD, LD and FA have been found at the C7 level without distinction between genders. On the other hand, the highest mean APD was evidenced at the C6 level and the highest mean LD was evidenced at the $\mathrm{C} 3$ level without distinction between genders. The highest mean values of FA were found at the $\mathrm{C} 3$ level in the female group and C6 in the male group. The mean values of the APD, LD and FA on the left side were greater than those of right side at all the levels. There was a tendency to increase the mean values of FA according to the age group. According to the anatomical variations of the transverse foramen, 57 individuals $(95 \%)$ of the whole sample presented at least a single anatomical variation and 25 individuals (42\%) more than three. Asymmetry was the most frequently variation identified ( 35 individuals $=58.3 \%$ ), followed by foramen duplication (32 individuals $=53.3 \%$ ), sulcus formation $(25$ individuals $=41.7 \%$ ), hypoplasia $(22$ individuals $=36.7 \%)$, agenesis $(5$ individuals $=8.3 \%)$, open foramen $(3$ individuals $=5 \%$ ) and finally a cervical rib in 1 individual $(1.7 \%)$. Finally, we determined the morphometric features of the transverse foramen by the tomographic images and anatomic variations were observed that justify their study prior cervical surgical procedures.
\end{abstract}

Keywords: Anatomical variation. Cervical vertebra. Transverse foramen. Cervical rib. Tomography. 


\section{LISTA DE FIGURAS}

Figura 1

Figura 2

Origem do Forame Transverso

Características das vértebras cervicais

Imagem tomográfica coronal (A) ilustrando a distância da margem medial do FT à crista medial da articulação uncovertebral(F) e imagem axial (B) ilustrando a borda do FT esquerdo medial à articulação uncovertebral.

Figura 4

Variações anatômicas

Figura 5

Artéria e veia vertebral, vista lateral.

Vértebra cervical esquemática ilustrando as estruturas anatômicas no FT.

Vias de abordagem que colocam em risco de lesão à artéria vertebral.

Figura 10 Imagens tomográficas ilustrando as variações anatômicas do FT.

Figura 11

Imagem tomográfica axial ilustrando a metodologia para a obtenção das medidas.

Tomografia em corte axial ilustrando a assimetria com o forame transverso esquerdo maior.

Figura 12

Figura 13

Tomografia em corte axial ilustrando duplicação unilateral (A) e bilateral (B).

Figura 14 Tomografia em corte axial ilustrando formação em sulco bilateral.

Figura 15

Tomografia em corte axial ilustrando hipoplasia unilateral (A) e bilateral (B).

Figura 16
Tomografia em corte axial ilustrando agenesia à esquerda (A), forame incompleto à esquerda (B) e costela cervical bilateral (C). 


\section{LISTA DE TABELAS}

Tabela 1

Tabela 2

Tabela 3

Tabela 4

Tabela 5

Tabela 6

Tabela 7

Tabela 8

Tabela 9

Tabela 10

Tabela 11

Tabela 12
Parâmetros medidos nas imagens axiais da TC com suas abreviações e descrições.

Variações anatômicas do forame transverso com suas abreviações e descrições.

dos FTs por gênero.

Valor-p das comparações dos diâmetros entre os lados (Direito e Esquerdo) para cada nível.

Valor-p das comparações dos diâmetros entre os gêneros (Masculino e Feminino) para cada nível e para cada lado.

Médias \pm DP da área dos forames transversos para cada nível e para cada lado.

Resumo da Análise descritiva das áreas dos forames para cada nível em $\mathrm{mm}^{2}$.

Valor-p das comparações das áreas dos forames entre os grupos por faixa etária para cada nível e para cada lado.

Coeficiente de correlação intraclasse (CCI) e o intervalo de confiança (IC) de $95 \%$ para a análise de concordância entre os dois avaliadores.

Registro de frequência e proporções das variações anatômicas nas vértebras por nível.

Registro de frequência e proporções das vértebras com assimetria dos forames transversos por gênero e por nível.

Frequências e proporções das variações anatômicas nos forames transversos por nível. 


\section{LISTA DE GRÁFICOS}

Gráfico 1 Comparação das médias das áreas dos forames entre os lados para cada nível no gênero masculino.

Gráfico 2 Comparação das médias das áreas dos forames entre os lados para cada nível no gênero feminino.

Gráfico 3

Comparação das médias das áreas dos forames entre os gêneros para cada nível por lado.

Gráfico 4

Comparação das médias das áreas dos forames entre os grupos por faixa etária para cada nível. 


\section{LISTA DE ABREVIATURAS}

$\begin{array}{lll}\text { AF } & - & \text { área do forame transverso } \\ \text { AG } & - & \text { agenesia } \\ \text { AS } & - & \text { assimetria } \\ \text { AV } & - & \text { artéria vertebral } \\ \text { CC } & - & \text { costela cervical } \\ \text { C1 } & - & \text { primeira vértebra cervical } \\ \text { C2 } & - & \text { segunda vértebra cervical } \\ \text { C3 } & - & \text { terceira vértebra cervical } \\ \text { C4 } & - & \text { quarta vértebra cervical } \\ \text { C5 } & - & \text { quinta vértebra cervical } \\ \text { C6 } & - & \text { sexta vértebra cervical } \\ \text { C7 } & - & \text { sétima vértebra cervical } \\ \text { DAP } & - & \text { diâmetro anteroposterior } \\ \text { DL } & - & \text { diâmetro lateral } \\ \text { DISH } & - & \text { doença hiperostótica familiar } \\ \text { DU } & - & \text { duplicação } \\ \text { FMRP-USP } & - & \text { Faculdade de Medicina de Ribeirão Preto da Universidade de São Paulo } \\ \text { FI } & - & \text { forame incompleto } \\ \text { FT } & - & \text { forame transverso } \\ \text { HS } & - & \text { hipoplasia } \\ \text { mm } & - & \text { milímetros } \\ \text { mm² } & - & \text { milímetros quadrados } \\ \text { SU } & - & \text { formação em sulco } \\ \text { TC } & \text { tomografia computadorizada } \\ & & \end{array}$




\section{Sumário}

1. INTRODUÇÃ

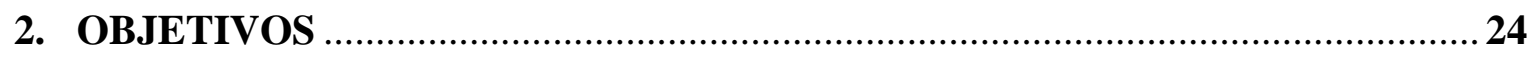

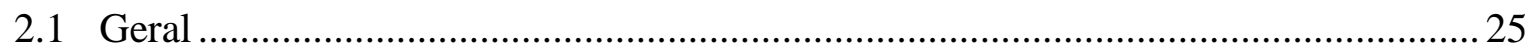

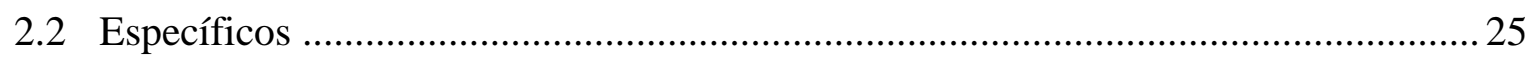

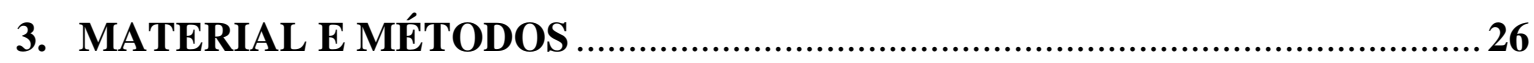

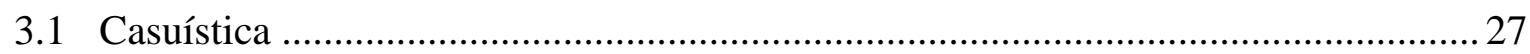

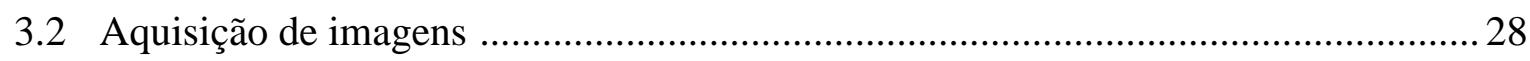

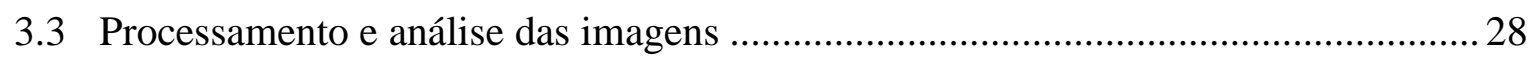

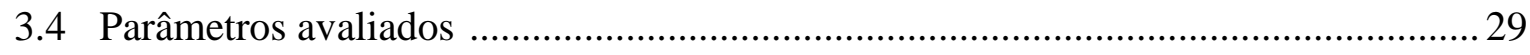

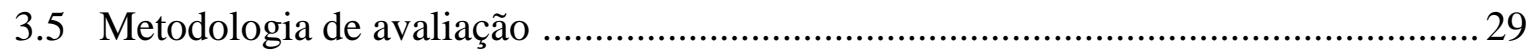

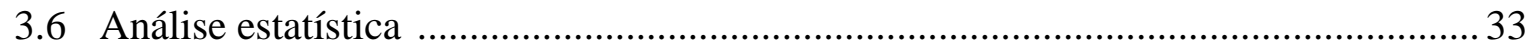

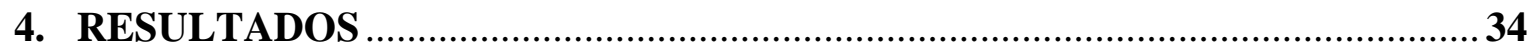

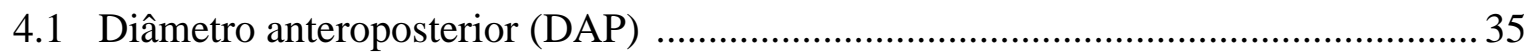

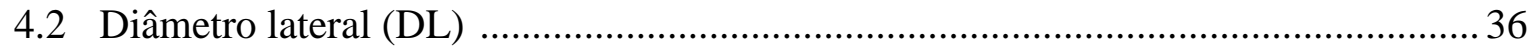

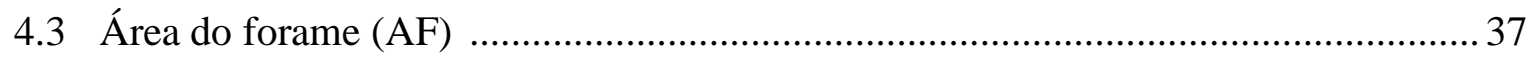

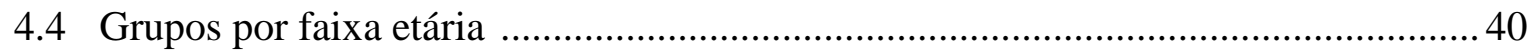

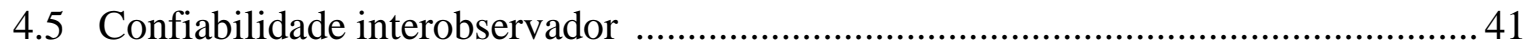

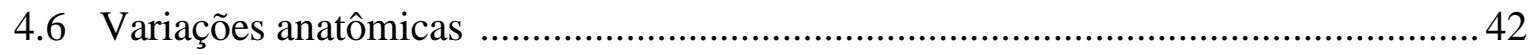

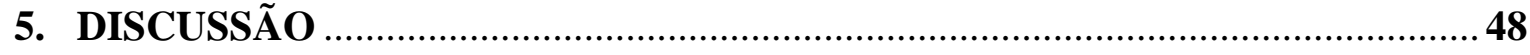

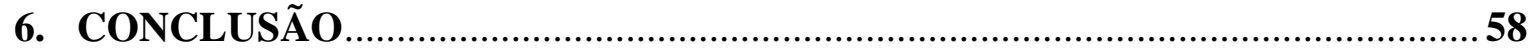

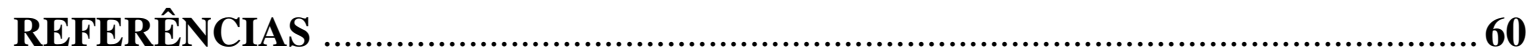

ANEXO A - Parecer Comitê de Ética em Pesquisa .......................................................65 
INTRODUÇÃO 


\section{INTRODUÇÃO}

O forame transverso (FT) (do latim foramen transversarium) é um orifício que se localiza na base dos processos transversos, ao lado do corpo das vértebras da coluna cervical (C1-C7) (JAÉN E., 1975). Tem origem a partir da fusão do vestígio do processo costal com o corpo vertebral e com o próprio processo transverso da vértebra cervical. Os processos costais primordiais formados durante a quinta semana de vida intrauterina iniciam sua ossificação na oitava semana de gestação formando a "barra costotransversa" que fusionados ao processo transverso dão origem ao forame do mesmo nome (Figura 1) (TAITZ; NATHAN; ARENSBURG, 1978).

Figura 1 - Origem do FT

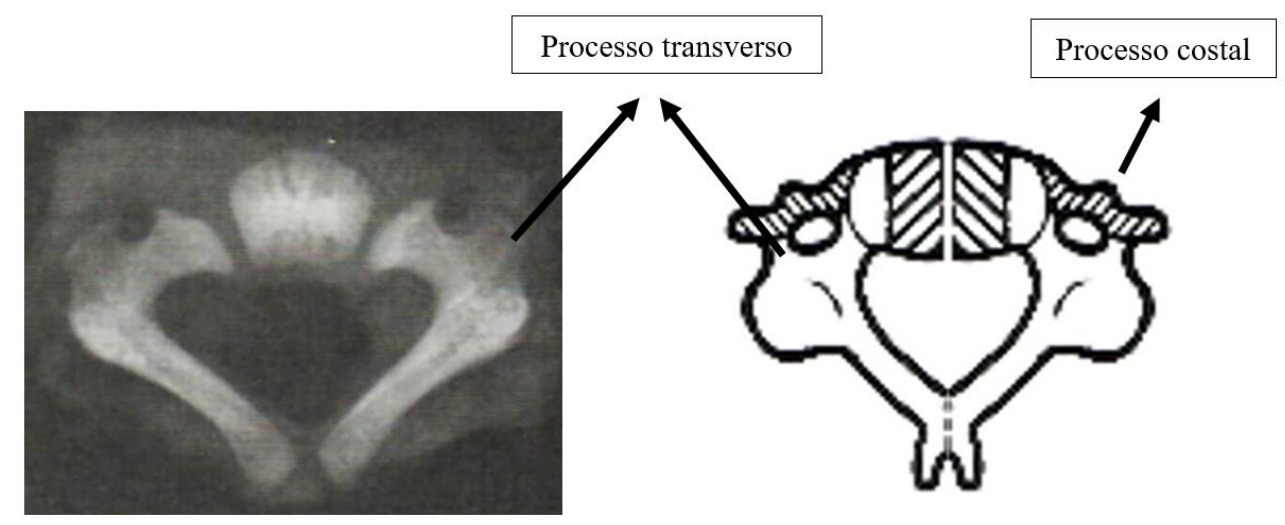

Fonte: Herkowitz et al. (2006)

Processo Costal Primordial (Barra costotransversa)

As vértebras cervicais possuem características gerais: o corpo vertebral, o canal vertebral, os pedículos, os processos transversos com seus forames do mesmo nome, as massas laterais com seus processos articulares superior e inferior, o processo espinhoso e as lâminas vertebrais. No entanto, existem ainda vértebras que apresentam características próprias, como o Atlas que não possui corpo vertebral, o Áxis com seu processo odontoide e a sétima vértebra cervical que apresenta o processo espinhoso mais proeminente da coluna cervical (Figura 2). Em suma, os níveis de C3, C4, C5 e C6 sãos definidos como vértebras típicas por possuírem características estruturais comuns. Já os níveis de C1(Atlas), C2(Áxis) e C7 (vértebra 
proeminente) são denominados como atípicos pelo resultado de suas características estruturais e funcionais particulares (THOMPSON, 2004).

Figura 2 - Características das vértebras cervicais

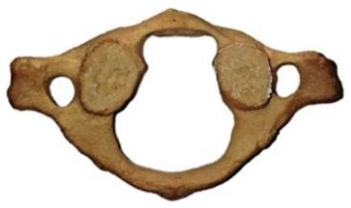

Atlas (C1)

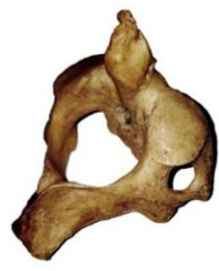

Áxis (C2)

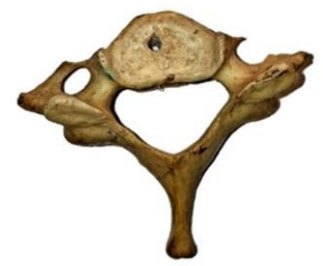

Proeminente (C7)

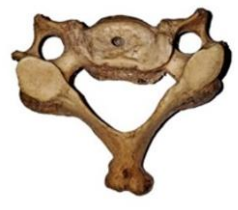

Vértebras típicas (C3-C6)

Fonte: o autor

Acompanhando essa divisão da anatomia da coluna cervical, o FT também apresenta características para cada grupo de vértebras (atípicas e típicas) que merecem ser destacadas. No Atlas, o FT está localizado ao lado das massas laterais e apresenta um formato elipsoide e oblíquo, além de ser considerado o maior da coluna cervical. Por outro lado, no Áxis, o FT se encontra no ângulo póstero inferior da faceta articular superior e anterior à faceta articular inferior da mesma vértebra. Diferente do Atlas, o forame do Áxis possui duas aberturas com formatos diferentes, sendo a abertura súperolateral predominantemente arredondada e a abertura ínferomedial elipsoide e oblíqua (THOMPSON, 2004). Conforme Taitz, Nathan e Arensburg (1978), a diferença de formato nas duas aberturas do FT de C2 se deve ao estresse mecânico produzido constantemente pelos vasos sanguíneos correndo no forame vertebral durante os movimentos da coluna cervical (flexão, extensão e rotação).

Finalmente, a última vértebra atípica (C7) possui o menor FT da coluna cervical com o menor diâmetro médio variando de 3,9 mm a 6,31 mm (CAGNIE et al., 2005; DEĞIRMENCI; YILMAZ, 2013; EVANGELOPOULOS, 2012; ZIBIS et al., 2018). Estudos relacionados à artéria vertebral (AV) e ao FT realizados com Angiotomografia computadorizada atribuem o menor tamanho do FT de C7 à ausência da AV passando por dentro do FT neste nível. Tal análise apoiaria a hipótese de que a presença ou ausência de vasos sanguíneos influenciaria no formato do FT (KIM et al., 2012; METIN TELLIOGLU et al., 2018; TAITZ; NATHAN; ARENSBURG, 1978). 
Nas vértebras típicas, os FTs apresentam características anatômicas similares. Dessa forma, estudos morfométricos foram realizados em conjunto. Quanto a sua localização, Curylo et al. (2000) demonstraram que, o FT situa-se lateral ao corpo vertebral a uma distância média de 5,5 mm da borda medial da articulação uncovertebral (articulação de Luschka). Assim, a articulação uncovertebral é considerada ponto de referência anatômico seguro, quando a via anterior à coluna cervical é uma opção cirúrgica para descompressões. No entanto, o grupo de Bruneau et al. (2006) relata que, em 2\% dos indivíduos, o FT invade o limite medial da articulação uncovertebral colocando em risco de lesão, os vasos sanguíneos contidos dentro do FT, durante procedimentos cirúrgicos (Figura 3) (BRUNEAU et al., 2006).

Figura 3 - Imagem tomográfica coronal (A) ilustrando a distância da margem medial do FT à crista medial da articulação uncovertebral(F) e imagem axial (B) ilustrando a borda do FT esquerdo medial à articulação uncovertebral.

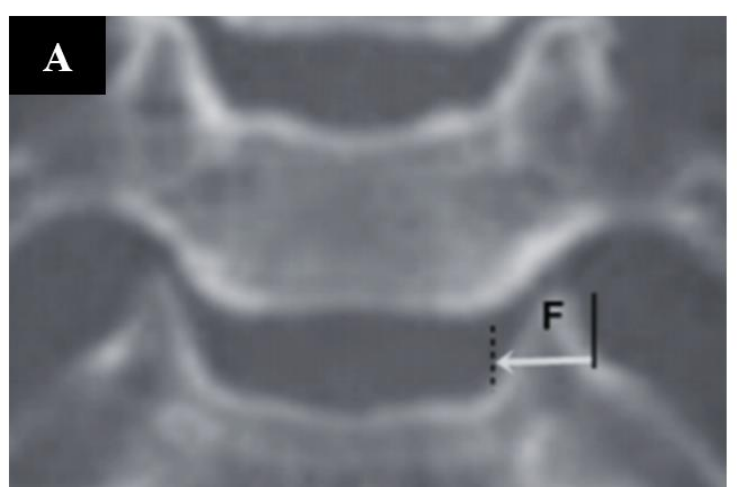

Fonte: Malla et al. (2018)

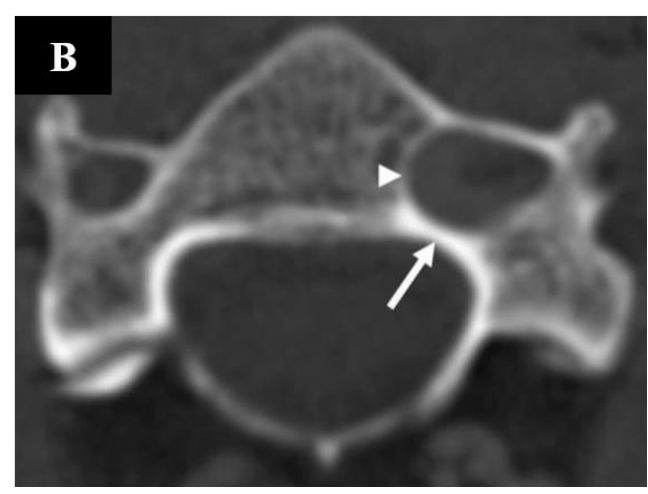

Fonte: Bruneau et al. (2006)

Além de dados morfométricos, variações anatômicas do FT também já foram relatadas na literatura. Entre as variações, encontramos: forame incompleto, reduzido ou hipoplásico, presença de sulco e de forames assimétricos, forame duplo ou triplo ou, em alguns casos, até a sua ausência (DEĞIRMENCI; YILMAZ, 2013; METIN TELLIOGLU et al., 2018) (Figura 4). Os achados foram obtidos em estudos de várias regiões do mundo realizados em peças anatômicas de cadáveres, em imagens tomográficas ou de ressonância magnética da coluna cervical, porém, nenhum deles abrangendo a população brasileira. A importância do estudo das variações anatômicas do FT reside no fato de que a sua presença pode modificar o curso anatômico de estruturas vasculonervosas ocasionando condições patológicas (KAYA et al., 2011). 
Figura 4 - Variações anatômicas

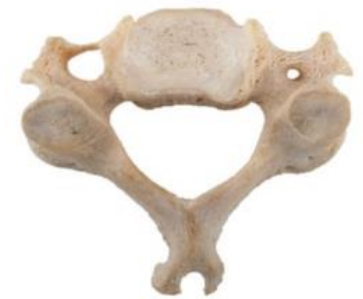

Hipoplasia à esquerda

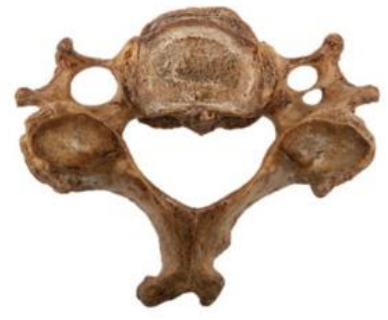

Duplicação à esquerda

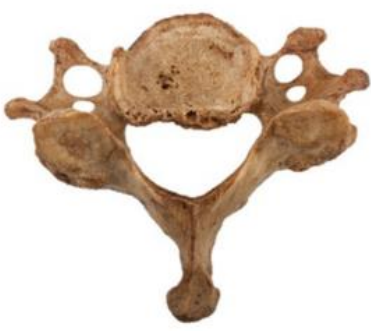

Duplicação bilateral

Fonte: Zibis et al. (2016)

O maior número de variações anatômicas se concentra na coluna cervical baixa (C3C7). Değirmenci e Yilmaz (2013) foram os primeiros a publicar dados de variações anatômicas obtidas por meio de imagens de tomografia computadorizada (TC) e identificaram variações principalmente nos níveis C5, C6 e C7. Na literatura, embora não exista uma causa bem definida para explicar as variações, especula-se que a configuração dos forames possa sofrer influência da AV (DEĞIRMENCI; YILMAZ, 2013), ou que seja resultado de alterações durante o desenvolvimento embrionário (JAÉN E., 1975; TAITZ; NATHAN; ARENSBURG, 1978).

Os FTs contêm AV, veias vertebrais e fibras nervosas simpáticas provenientes dos gânglios estrelado, médio e inferior (CAGNIE et al., 2005). A AV como elemento mais representativo do FT, após originar-se da artéria subclávia (à Esquerda $=94.2 \%$ e à Direita $=$ 99,8\%) na maior parte dos casos (MEILA et al., 2012) entra no FT normalmente ao nível de C6 em 93\% dos indivíduos (BRUNEAU et al., 2006; KAJIMOTO et al., 2007). No entanto, pode apresentar entrada anômala em 7\% dos indivíduos, sendo o nível de C5 o mais frequente, seguido por C4, C7 e C3 (BRUNEAU et al., 2006). Uma vez dentro do FT, a artéria ocupa o espaço mais medial do forame (ZHAO et al., 2008), ascendendo cranialmente até alcançar o FT do nível C2. Dali emerge e segue em direção lateral e superior até o FT do Atlas para continuar seu trajeto medialmente sobre o sulco da AV no arco posterior do Atlas até entrar no forame magno e anastomosar-se com a AV contralateral dando origem à artéria basilar (ESKANDER et al., 2010) (Figura 5). 
Figura 5 - Artéria e veia vertebral, vista lateral.

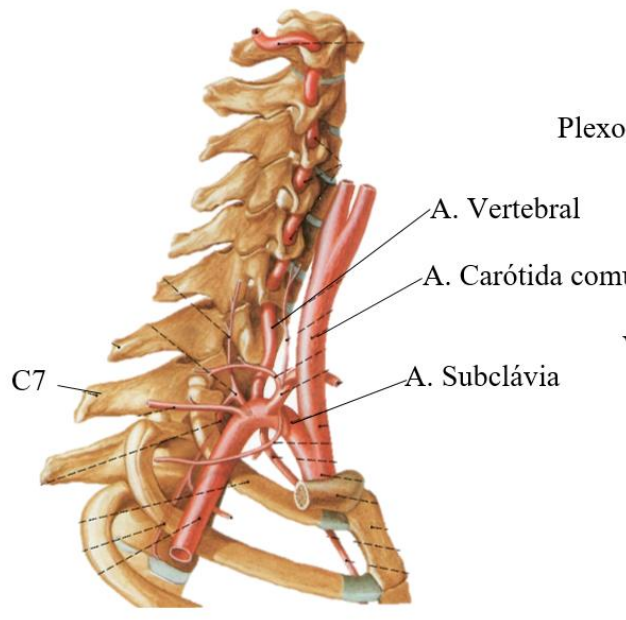

Fonte: Putz e Pabst (2000)

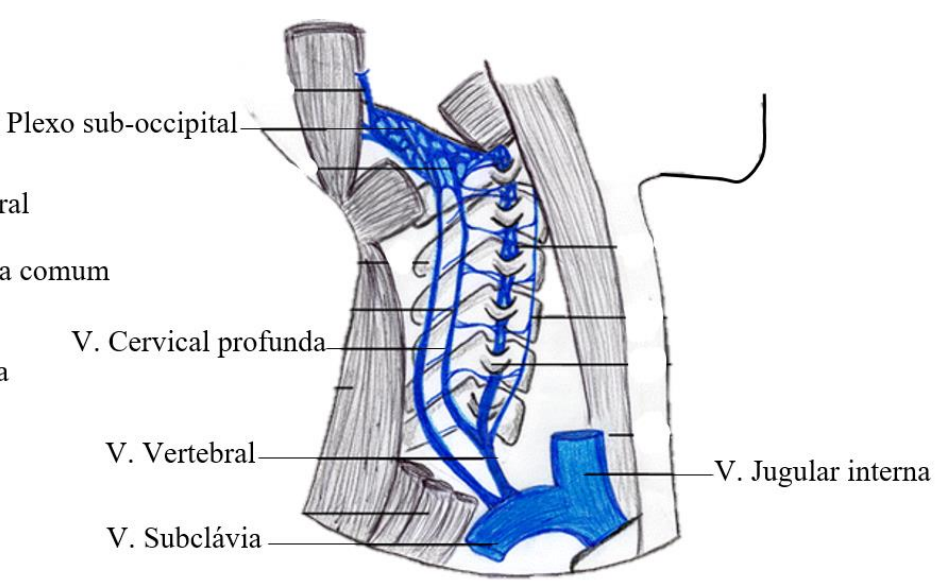

Fonte: Magro et al. (2014)

A veia vertebral é descrita como única, ou às vezes, como vários troncos formando um plexo ao redor da AV. Após a sua origem, no plexo suboccipital, a veia vertebral entra no FT do Atlas e, ocupando o espaço anterolateral à AV, desce até a sétima vértebra cervical, raramente até a sexta, e finaliza seu trajeto drenando na região póstero-inferior da veia subclávia (MAGRO et al., 2014) (Figura 5) (Figura 6).

Figura 6 -Vértebra cervical esquemática ilustrando as estruturas anatômicas no FT.

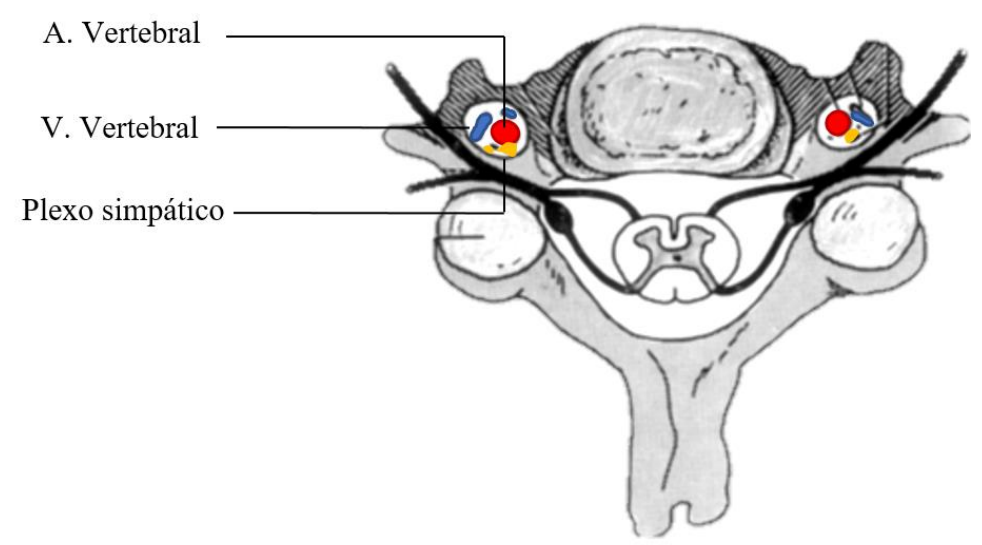

Fonte: Taitz, Nathan e Arensburg (1978) 
Entre as estruturas anatômicas que estão em risco durante a abordagem cirúrgica da coluna cervical, destacam-se as da AV. Estudos acerca da incidência de lesão da AV durante procedimentos cirúrgicos envolvendo a coluna cervical relatam $8,2 \%$ quando a abordagem cirúrgica é realizada pela via posterior (NEO et al., 2008) e 0,5\% quando o procedimento é realizado pela via anterior (BURKE; GERSZTEN; WELCH, 2005; NEO et al., 2008) (Figura 7).

Figura 7 - Vias de abordagem que colocam em risco de lesão à AV.

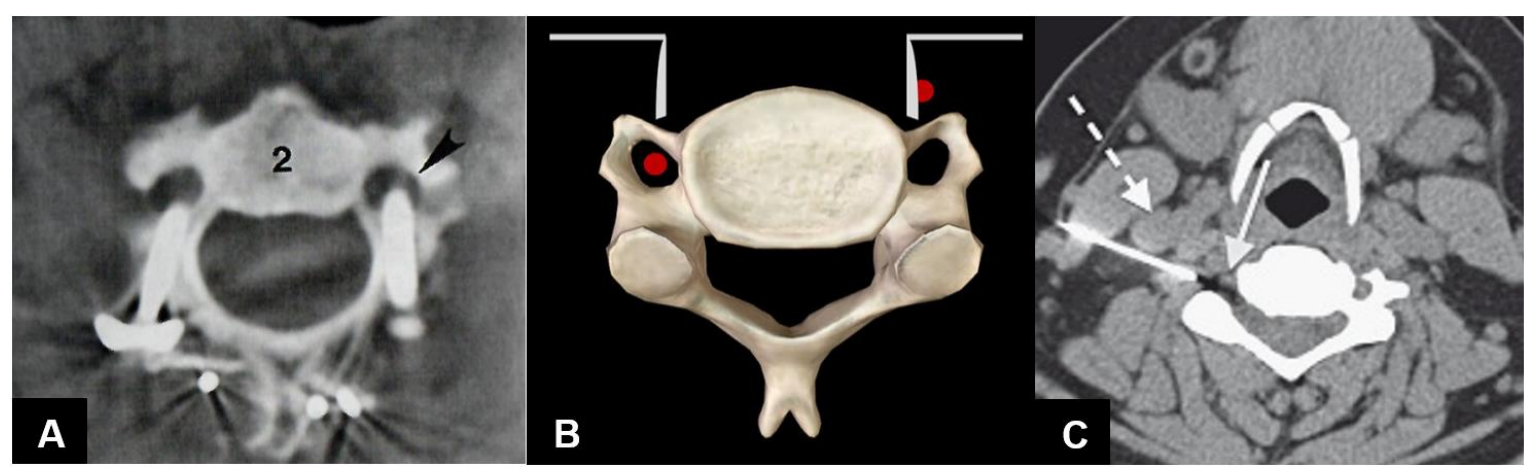

Fonte: Herkowitz et al. (2006); Zibis et al. (2018); Fitzgerald, Bartynski e Collins (2013)

Parafusos de massa lateral mal posicionados invadindo os FTs (A); Representação esquemática do mecanismo de lesão da $\mathrm{AV}$ provocado por afastadores na abordagem anterior à coluna cervical (B); Imagem tomográfica ilustrando a intersecção da agulha com a AV em um procedimento para tratamento de dor radicular $(\mathrm{C})$.

As massas laterais e os pedículos da coluna cervical têm sido utilizados para a colocação de implantes. Umas das complicações relatadas para essas técnicas é a lesão da AV, localizada anterior à massa lateral e anterolateral ao pedículo (Figura 7 - A). Estudos morfométricos foram realizados para identificar pontos de referência anatômicos que aumentem a acurácia ao inserir parafusos nessas estruturas ósseas, assim como para evitar a lesão das estruturas anatômicas dentro do FT. Panjabi et al. (2000), em um estudo anatômico, mostraram que a cortical mais fina do pedículo corresponde à cortical do FT, o que facilitaria a sua ruptura durante um procedimento cirúrgico, colocando em risco de lesão a AV quando a opção for a inserção do parafuso pedicular. Por outro lado, vários autores têm desenvolvido técnicas para a colocação de parafusos na massa lateral testando distintos trajetos a fim de obter maior estabilidade, resistência ao arrancamento e ao mesmo tempo, quando possível, menor risco de lesão 
inadvertida de estruturas anatômicas adjacentes à massa lateral (ANDERSON et al., 1991; JEANNERET et al., 1991; ROY-CAMILLE et al., 1992).

A abordagem anterior foi popularizada para o tratamento de doenças que acometem a coluna média e anterior da coluna cervical. Na revisão realizada por Guan et al. (2017), a lesão da AV diagnosticada, durante ou após os procedimentos cirúrgicos na coluna cervical, esteve associada mais comumente a doenças degenerativas (64\%), tumores (14\%) e trauma (9\%). A incidência de lesão da AV nas discectomias cervicais por via anterior é baixa na literatura, porém potencialmente fatal. Além disso, estimam-se incidências maiores para cirurgias mais invasivas (corpectomia) (LO; NAGARAJA; SAXENA, 2017). Entre os fatores de risco para a lesão da AV, destacam-se a extensa descompressão lateral, a perda dos parâmetros anatômicos e a presença de variações anatômicas tanto do FT quanto da AV (GUAN et al., 2017).

Também foram observadas na literatura lesões da AV por procedimentos cirúrgicos percutâneos (Figura 7 - C). Scanlon et al. (2007) identificaram complicações envolvendo a AV em uma série de casos submetidos à injeção foraminal e epidural na coluna cervical somente em 5,5\%. No entanto, o resultado das complicações com desfecho fatal foi de 44,4\%. Para minimizar o risco de complicações, os autores recomendam meticulosa avaliação préoperatória, cuidadosa manipulação intraoperatória e uso de imagens em tempo real (SCANLON et al., 2007).

As lesões vasculares, na maior parte das vezes, são consideradas iatrogênicas, pois ocorrem durante o procedimento cirúrgico (GUAN et al., 2017). Sendo assim, o conhecimento detalhado da anatomia normal e o diagnóstico precoce das variações anatômicas na coluna cervical podem reduzir o número de complicações cirúrgicas (BIBLE et al., 2016). Tem sido observado na literatura que existe uma relação entre a anatomia da AV e a do FT (KIM et al., 2012; METIN TELLIOGLU et al., 2018). Conforme Kim et al. (2012), o tamanho da AV é diretamente proporcional ao tamanho do FT. Dessa maneira, destaca-se a importância do conhecimento das variações anatômicas e morfométricas do FT como uma referência confiável da anatomia e do trajeto da AV (KIM et al., 2012).

Para o estudo morfométrico do FT da coluna cervical, algumas técnicas foram descritas mostrando níveis altos de confiabilidade e reprodutibilidade das medidas, incluindo TC, ressonância nuclear magnética e a avaliação direta da peça anatômica de cadáver (CAGNIE et al., 2005; KIM et al., 2012; MOLINET GUERRA; ROBLES FUENTES; ROA, 2017; 
SUREKA et al., 2018; ZIBIS et al., 2018). A avaliação da peça anatômica é realizada diretamente com um paquímetro, instrumento ajustável desenvolvido na França em 1.631 por Pierre Vernier. É utilizado amplamente em laboratórios científicos para vários fins nos quais é necessário realizar medidas lineares e precisas entre dois pontos ("vernier caliper -- Britannica Academic", [s.d.]). Taitz, Nathan e Arensburg (1978) avaliaram 480 forames de 36 esqueletos e, a partir de medidas dos diâmetros do FT, obtiveram diferentes formatos de forame por meio de uma fórmula denominada coeficiente de redondeza. Mais tarde, aplicando a mesma técnica, Gupta et al. (2014) registraram medidas de diâmetro do FT, inclusive menores do que de $2 \mathrm{~mm}$.

Para a avaliação de estruturas ósseas, a TC tem se mostrado mais eficaz que outros métodos devido à detecção de diferença de contrastes mínimos que produzem maior detalhe das estruturas ósseas. Além disso, os avanços na criação de ferramentas nos programas que fazem a avaliação das imagens tomográficas tornam as medidas anatômicas de estruturas ósseas mais viáveis e precisas (CAGNIE et al., 2005; DEĞIRMENCI; YILMAZ, 2013; SUREKA et al., 2018; ZIBIS et al., 2018). As imagens tomográficas, além de representar um aumento de dez vezes a resolução de contraste quando comparadas com radiografias convencionais, oferecem cortes anatômicos em diferentes planos da estrutura anatômica em estudo sem superposição de outras imagens (GUPTA et al., 2014). Quando necessário, esse método pode ser complementado com ressonância magnética se o objetivo é principalmente a avaliação de partes moles, inclusive a realização de exames invasivos como a angiografia associada à TC ou ressonância magnética quando o objetivo é a avaliação dos vasos sanguíneos (BRUNEAU et al., 2006; KIM et al., 2012; ZIBIS et al., 2018).

Considerando as possíveis complicações relacionadas às técnicas cirúrgicas envolvendo o tratamento de doenças que acometem a coluna cervical e que colocam em risco as estruturas anatômicas contidas no FT, o estudo da anatomia pré-operatória é fundamental. Assim, o objetivo do estudo é determinar as características morfométricas do FT em uma amostra da população brasileira por meio do estudo de imagens tomográficas. 
OBJETIVOS 


\section{OBJETIVOS}

\subsection{GERAL}

Determinar as características morfométricas e anatômicas dos forames transversos das vértebras de $\mathrm{C} 3$ a $\mathrm{C} 7$ utilizando imagens de tomografia computadorizada.

\subsection{ESPECIFICOS}

- Comparar nossos resultados com os relatados previamente na literatura;

- Estabelecer a confiabilidade interobservador da metodologia empregada na avaliação das medidas;

- Comparar os resultados das medidas obtidas com relação ao gênero e à faixa etária. 
MATERIAL E MÉTODOS 


\section{MATERIAL E MÉTODOS}

\subsection{Casuística}

Trata-se de estudo observacional a partir de um banco de dados, aprovado pelo Comitê de Ética em Pesquisa do Hospital das Clínicas da Faculdade de Medicina de Ribeirão Preto da Universidade de São Paulo (FMRP-USP) (Anexo A). Foi solicitada e concedida a dispensa do termo de consentimento livre e esclarecido da pesquisa, por se tratar de um estudo cujo objetivo foi o de analisar as características anatômicas de estruturas ósseas a partir de imagens de TC adquiridas na Unidade de Emergência do Hospital das Clínicas da FMRP-USP. Vale destacar que os exames foram inicialmente solicitados para outros fins, mas a utilização de suas imagens, neste trabalho, não acarretou prejuízo no tratamento pregresso ou futuro dos pacientes incluídos.

O desenho do estudo baseou-se na avaliação de imagens tomográficas da coluna cervical a partir do nível de C3 até o nível de C7, concentrando as medidas no FT. Retrospectivamente, selecionamos imagens tomográficas cervicais de 60 indivíduos (30 do gênero feminino e 30 do masculino) que foram obtidas de pacientes atendidos na Unidade de Emergência do Hospital das Clínicas da FMRP-USP, no período de janeiro de 2008 a dezembro de 2015. A idade média geral foi de $43 \pm 18$ (variação de 18 a 83), sendo a idade média nos homens de $39 \pm 17$ anos (variação de 18 a 83 anos) e nas mulheres de $47 \pm 19$ anos (variação de 21 a 82 anos).

Os critérios de exclusão utilizados neste estudo foram: idade inferior a 18 anos, cirurgia prévia na coluna vertebral cervical, presença das afecções da coluna vertebral cervical como fraturas, tumores, infecções, espondilite anquilosante e doença hiperostótica familiar (DISH). Já os critérios de inclusão envolveram: idade superior a 18 anos e a ausência de afecções ou cirurgias prévias na coluna vertebral cervical. 


\subsection{Aquisição de imagens}

Os exames de imagem foram realizados em um aparelho de TC (Brilliance CT Big Bore 16-slice, Philips Healthcare, Cleveland, Ohio) na Unidade de Emergência do Hospital das Clínicas da FMRP-USP (Figura 8).

Figura 8 - Aparelho de Tomografia - Brilliance CT Big Bore 16-slice
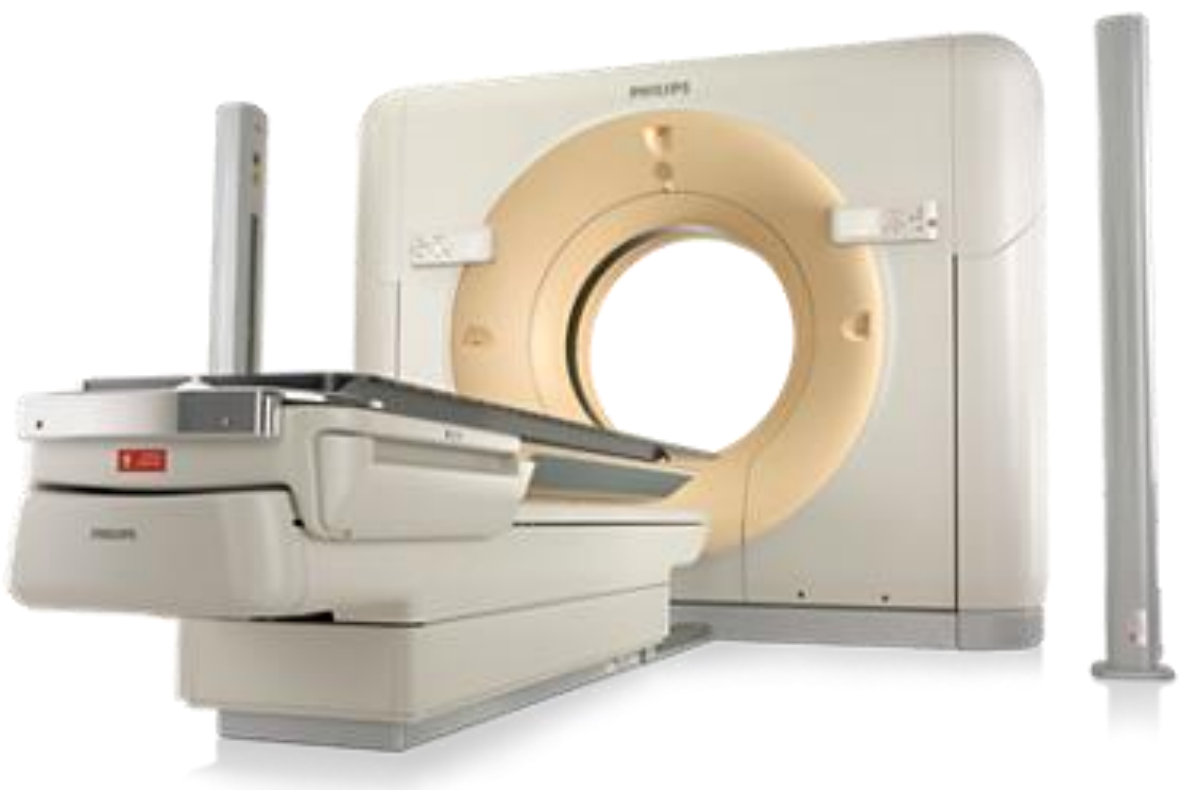

Fonte: ("Philips - Brilliance CT Big Bore Radiology CT scanner", [s.d.])

\subsection{Processamento e análise das imagens}

As reconstruções das imagens do aparelho de TC foram obtidas, utilizando-se cortes com uma espessura de 1 a $3 \mathrm{~mm}$ nos planos sagital e axial. A avaliação das imagens foi realizada por meio do programa de imagem OsiriX MD, versão 7.0.2 (Pixmeo SARL, Bernex, Suíça), que possui ferramentas de medições lineares e de área. Além disso, permite visualizar simultaneamente dois planos das imagens, facilitando a identificação do nível do forame (C3 a C7) na linha média do plano sagital e, ao mesmo tempo, a avaliação das medidas no plano axial. 


\subsection{Parâmetros avaliados}

Os parâmetros axiais do FT avaliados incluíram o diâmetro anteroposterior (DAP), o diâmetro lateral (DL), a área (AF) e a presença de variações anatômicas.

Os forames com variações anatômicas de agenesia (AG), hipoplasia (HS) $(<2 \mathrm{~mm})$ e forame aberto (FI) foram excluídos das avaliações dos diâmetros e áreas. Entre os que apresentaram duplicação (DU), o maior forame foi avaliado e as medidas que apresentassem assimetria (AS) foram incluídas nas avaliações.

\subsection{Metodologia de avaliação}

O desafio usual de transpor os dados de exames de imagem em informação útil envolve a dificuldade em delinear estruturas tridimensionais, tais como o FT, em duas dimensões. Para obter os dados de maneira mais clinicamente aplicável a partir das imagens de TC, inicialmente, utilizamos a avaliação triplanar (axial, sagital e coronal) para ajustar a inclinação do plano sagital, alinhando o processo odontoide de C2 com o processo espinhoso de C7 no corte coronal, seguido pelo alinhamento do plano axial por meio da placa terminal superior da vértebra a ser estudada (Figura 9). Dessa forma, obteve-se a melhor imagem axial do FT. A seguir, utilizamos os planos sagital e axial simultaneamente para a medida de todos os parâmetros.

Dois investigadores independentes realizaram as medidas dos parâmetros relacionados, utilizando o programa de imagem OsiriX MD para estimar a confiabilidade interobservador.

A lista de terminologia de todos os parâmetros medidos, com suas respectivas abreviações e descrições, está sumarizada na Tabela 1. A lista de variações anatômicas do FT bem como suas abreviações e descrições estão relacionadas na Tabela 2. Já a ilustração das variações consta na Figura 10. 
Figura 9 - Imagem tomográfica ilustrando o alinhamento dos planos coronal, sagital e axial.

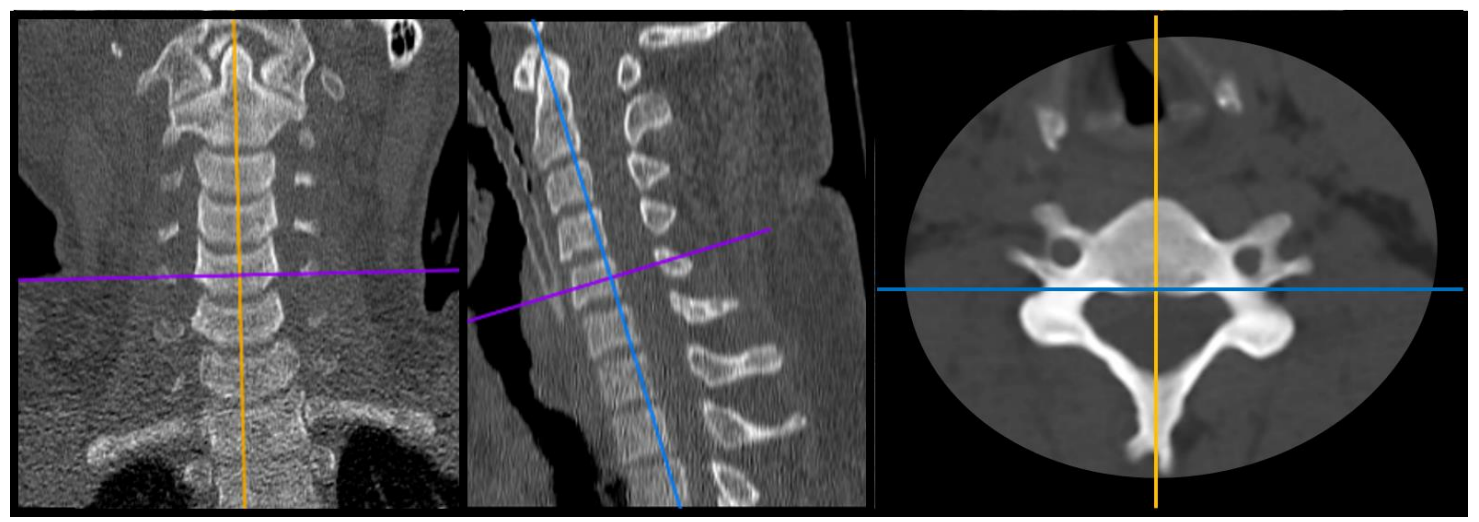

Fonte: O autor

Tabela 1 - Parâmetros medidos nas imagens axiais da TC com suas abreviações e descrições.

\begin{tabular}{lll}
\hline Medida & Abreviação & Descrição \\
\hline
\end{tabular}

Distância, em milímetros, entre a cortical anterior

Diâmetro anteroposterior DAP e a posterior do forame transverso na imagem axial.

Diâmetro lateral

DL Distância em milímetros entre a cortical medial e a lateral do forame transverso na imagem axial.

Linha que circunda a cortical do forame

Área do forame

AF transverso, transformada em milímetros quadrados pelo programa de imagem. 
Tabela 2 - Variações anatômicas do FT com suas abreviações e descrições

Variação anatômica Abreviação Descrição

Agenesia

Assimetria

Costela cervical

Duplicação

Forame incompleto

Formação em Sulco

Hipoplasia
AG Ausência de forame transverso.

AS

Quando a AF é 1,5 vezes maior que a do lado contralateral e não possui nenhuma outra variação anatômica.

Quando o ramo anterior do processo transverso se torna um osso separado, formando uma costela rudimentar.

DU Dois forames transversos separados por um septo ósseo.

FI Ausência de fechamento completo do forame transverso.

SU

Presença de entalhe que não é totalmente separado por um septo ósseo.

HS Quando algum diâmetro for menor que $2 \mathrm{~mm}$. 
Figura 10 - Imagens tomográficas ilustrando as variações anatômicas do FT.
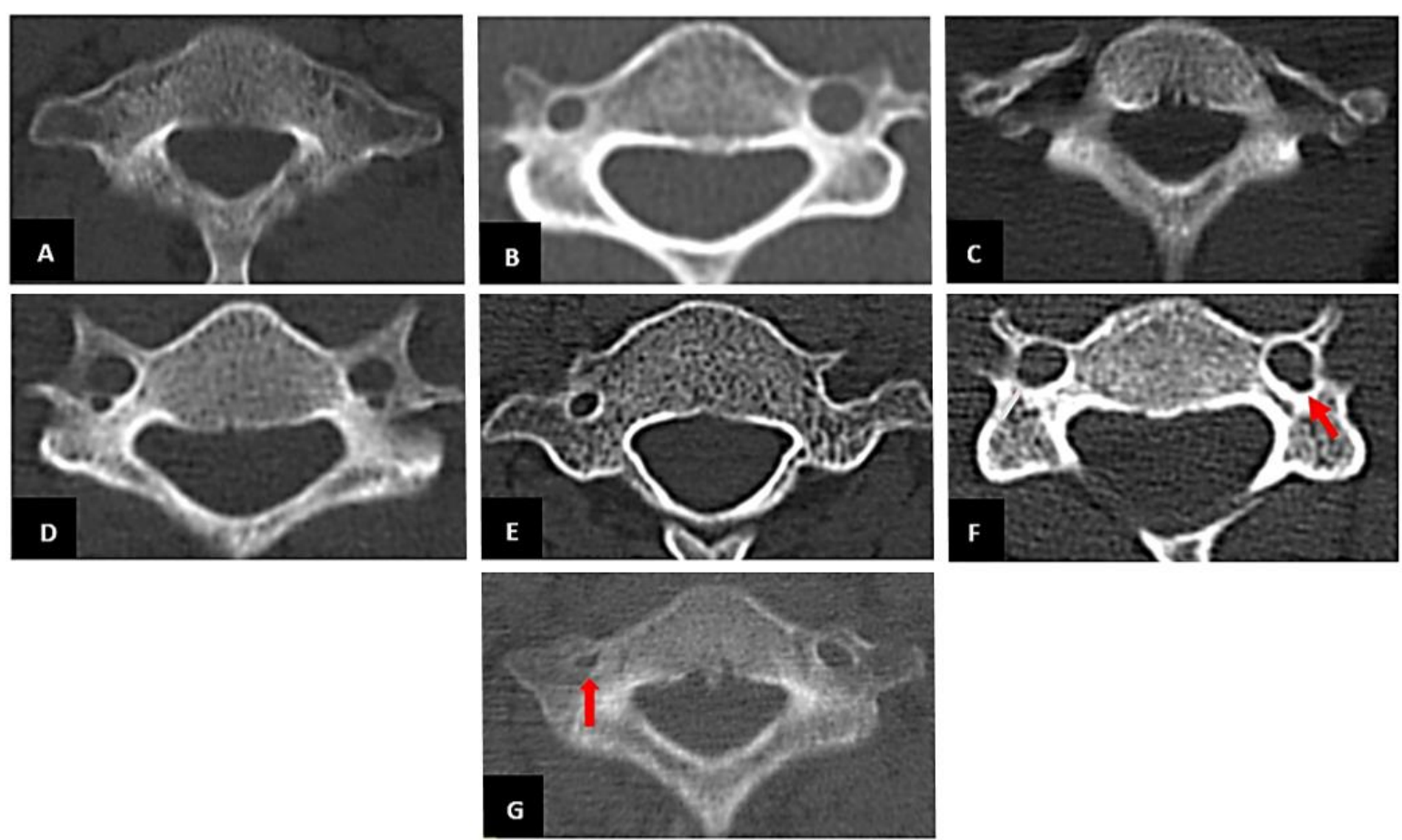

Fonte: $\mathrm{O}$ autor

AG do forame à direita (A); Forames assimétricos (B); Costelas cervicais bilaterais (C); DU bilateral (D); FI à esquerda (E); SU (seta) (F); Forame hipoplásico à direita (seta) (D).

A metodologia de realização das medidas está ilustrada na Figura 11. Os parâmetros lineares foram medidos em milímetros e a AF, em milímetros quadrados.

Figura 11 - Imagem tomográfica axial ilustrando a metodologia para a obtenção das medidas.

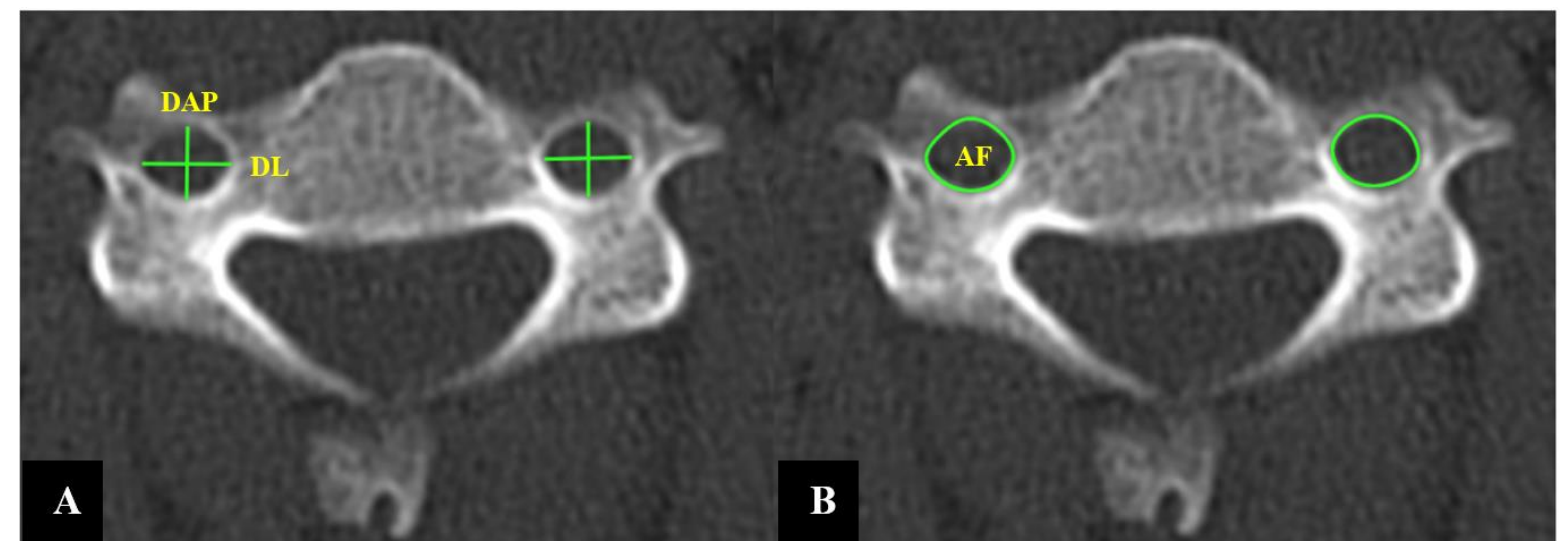

DAP - Diâmetro anteroposterior e DL - Diâmetro lateral (A); AF - Área do forame (B) 


\subsection{Análise estatística}

Em um total de 600 forames de 300 vértebras dos níveis de $\mathrm{C} 3$ a C7, foram calculados a média, o desvio padrão, o valor mínimo e o máximo dos diâmetros e das AFs por meio do programa Excel-2016.

Os cálculos mencionados foram realizados para cada nível para os pacientes do sexo masculino e feminino separadamente. Além disso, a amostra foi dividida em 3 grupos de acordo com a faixa etária, sendo o grupo 1 formado por pacientes de 18 a 40 anos; o grupo 2, por pacientes de 41 a 60 anos e o grupo 3, por pacientes acima de 60 anos.

Foram realizadas 3.600 medidas que foram empregadas para determinar as diferenças e comparar todos os parâmetros. Os valores das medidas dos FTs (DAP e DL) foram comparados entre os gêneros e entre os lados, em cada nível vertebral, por meio do teste t de Student. Os valores das medidas das AFs foram comparados entre os diferentes grupos etários em cada nível vertebral e entre os lados direito e esquerdo por meio do modelo linear de efeito misto (SCHALL, 1991).

A confiabilidade intraobservador foi estimada utilizando-se o coeficiente de correlação intraclasse (CCI) para as medidas tomográficas. A confiabilidade foi considerada muito fraca para valores entre 0 e 0,2; fraca para valores entre 0,21 e 0,4 ; moderada para valores entre 0,41 e 0,6; substancial ou boa para valores entre 0,61 e 0,8 e quase perfeita ou muito boa para valores entre 0,81 e 1,0 (FLEISS; COHEN, 1973). Utilizamos um nível de significância de 5\%. Todos os parâmetros foram armazenados em uma planilha e estudados por meio do programa SAS 9, 2003.

Por fim, analisamos a frequência e proporções das variações anatômicas dos FTs: AG, CC, DU, FI, SU, HS e AS. A concordância entre os observadores para a identificar as variações na amostra foi realizada por meio do coeficiente de concordância de Kappa com um nível de significância de 5\% e todos os registros foram armazenados e analisados por meio do programa IBM SPSS Statistics 24.0, 2016. 
RESULTADOS 


\section{RESULTADOS}

Foram selecionadas, aleatoriamente, imagens tomográficas cervicais de 60 indivíduos (30 do gênero feminino e 30 do masculino), resultando em um total de 600 FTs avaliados, incluindo os níveis vertebrais cervicais de C3 a C7.

\subsection{Diâmetro anteroposterior (DAP)}

O DAP médio variou de 3,88 a 6,05 mm (Tabela 3). O menor DAP médio foi encontrado no nível C7 em ambos os gêneros. Assim, nos pacientes do gênero feminino, o menor valor encontrado foi de 4,31 mm, enquanto, nos do gênero masculino, o menor valor encontrado foi de 3,88 $\mathrm{mm}$. Por outro lado, o maior DAP médio foi evidenciado em C6, também em ambos os gêneros. Enquanto para o grupo do gênero feminino o maior valor médio foi de 5,56 mm, no grupo do gênero masculino, o maior valor médio encontrado foi de $6,05 \mathrm{~mm}$.

Não foi possível perceber uma tendência ao aumento ou à diminuição do valor do DAP médio conforme avançamos de proximal para distal na coluna cervical (Tabela 3). O DAP médio encontrado foi maior no lado esquerdo, quando comparado ao lado direito nos níveis de C3 a C6 $(\mathrm{P}<0,05)$. Não houve diferença estatisticamente significativa no nível C7 $(\mathrm{P}>0,05)$ (Tabela 4). Quando comparado entre os gêneros, houve diferença estatística na média do DAP somente no nível C3 à direita, e nos níveis C5 e C6 à esquerda (Tabela 5).

Tabela 3 - Médias \pm DP dos diâmetros anteroposterior (DAP) e lateral (DL) dos FTs por gênero.

\begin{tabular}{ccccc|cccc}
\hline & \multicolumn{4}{c|}{ DAP $(\mathbf{m m} \pm \mathbf{D P})$} & \multicolumn{4}{c}{ DL $(\mathbf{m m} \pm \mathbf{D P})$} \\
Nível & \multicolumn{2}{c}{ Masculino } & \multicolumn{2}{c|}{ Feminino } & \multicolumn{2}{c}{ Masculino } & \multicolumn{2}{c}{ Feminino } \\
& $\mathbf{E}$ & $\mathbf{D}$ & $\mathbf{E}$ & $\mathbf{D}$ & $\mathbf{E}$ & $\mathbf{D}$ & E & D \\
\hline C3 & $5,20 \pm 0,67$ & $4,85 \pm 0,61$ & $5,36 \pm 0,57$ & $5,20 \pm 0,58$ & $6,46 \pm 0,78$ & $6,10 \pm 0,80$ & $6,40 \pm 0,76$ & $6,14 \pm 0,62$ \\
C4 & $5,27 \pm 0,69$ & $4,90 \pm 0,58$ & $5,28 \pm 0,53$ & $5,10 \pm 0,72$ & $6,43 \pm 0,85$ & $5,85 \pm 0,97$ & $6,27 \pm 0,77$ & $5,89 \pm 1,01$ \\
C5 & $5,62 \pm 0,81$ & $5,31 \pm 0,88$ & $5,31 \pm 0,70$ & $5,14 \pm 0,83$ & $6,29 \pm 0,91$ & $5,94 \pm 1,07$ & $5,93 \pm 0,66$ & $5,61 \pm 0,80$ \\
C6 & $6,05 \pm 1,26$ & $5,29 \pm 1,26$ & $5,56 \pm 1,23$ & $4,97 \pm 1,07$ & $6,11 \pm 0,92$ & $5,78 \pm 1,01$ & $5,87 \pm 1,23$ & $5,71 \pm 1,08$ \\
C7 & $3,88 \pm 1,26$ & $3,96 \pm 1,41$ & $4,31 \pm 1,10$ & $4,35 \pm 1,32$ & $4,49 \pm 1,30$ & $4,44 \pm 1,23$ & $4,80 \pm 1,37$ & $4,81 \pm 1,27$ \\
\hline
\end{tabular}

E-lado esquerdo; D-lado direito; DAP-Diâmetro anteroposterior; DL-Diâmetro lateral; mm- milímetros; DP - Desvio padrão. 
Tabela 4 - Valor-p das comparações dos diâmetros entre os lados (Direito e Esquerdo) para cada nível.

\begin{tabular}{clrlrl}
\hline Diâmetro & C3 & C4 & C5 & C6 & C7 \\
\hline DAP & $\mathbf{0 , 0 0 2}$ & $\mathbf{0 , 0 0 1}$ & $\mathbf{0 , 0 2 2}$ & $\mathbf{0}$ & 0,738 \\
DL & $\mathbf{0 , 0 0 1}$ & $\mathbf{0}$ & $\mathbf{0 , 0 0 4}$ & 0,085 & 0,928 \\
\hline
\end{tabular}

DAP - Diâmetro anteroposterior; DL - Diâmetro lateral.

Tabela 5 - Valor-p das comparações dos diâmetros entre os gêneros (Masculino e Feminino) para cada nível e para cada lado.

\begin{tabular}{ccccccc}
\hline Lado & Diâmetro & $\mathbf{C 3}$ & $\mathbf{C 4}$ & $\mathbf{C 5}$ & $\mathbf{C 6}$ & $\mathbf{C 7}$ \\
\hline \multirow{2}{*}{ E } & DAP & 0,159 & 0,937 & $\mathbf{0 , 0 2 6}$ & $\mathbf{0 , 0 3 6}$ & 0,079 \\
& DL & 0,647 & 0,274 & $\mathbf{0 , 0 1 5}$ & 0,228 & 0,252 \\
\hline \multirow{2}{*}{ D } & DAP & $\mathbf{0 , 0 0 2}$ & 0,100 & 0,283 & 0,143 & 0,170 \\
& DL & 0,722 & 0,830 & 0,062 & 0,741 & 0,156 \\
\hline
\end{tabular}

Legenda: E - Esquerdo; D - Direito; DAP - Diâmetro anteroposterior; DL - Diâmetro lateral.

\subsection{Diâmetro lateral (DL)}

O DL médio variou de 4,44 a 6,46 mm (Tabela 3). O menor DL médio foi encontrado no nível C7 em ambos os gêneros. Assim, nos pacientes do gênero feminino, o menor valor encontrado foi de 4,8 mm, enquanto, nos do gênero masculino, o menor valor encontrado foi de 4,44 mm. Por outro lado, o maior DL médio foi evidenciado em C3, também em ambos os gêneros. Enquanto para o grupo do gênero feminino o maior valor médio foi de $6,40 \mathrm{~mm}$, no grupo do gênero masculino, o maior valor médio encontrado foi de $6,46 \mathrm{~mm}$.

Foi possível perceber uma tendência à diminuição do valor do DL médio conforme avançamos de proximal para distal na coluna cervical (Tabela 3). O DL médio encontrado foi maior no lado esquerdo, quando comparado ao lado direito nos níveis de C3 a C5 (P<0,05), mas não houve diferença estatisticamente significativa nos níveis C6 e C7 (P>0,05) (Tabela 4). Ao se comparar entre os gêneros, houve diferença estatística na média do DL apenas no nível C5 à esquerda (Tabela 5). 


\section{3 Área do forame (AF)}

A média da AF variou de 14,74 a 29,48 $\mathrm{mm}^{2}$ (Tabela 6). A menor AF média foi encontrada em C7 em ambos os gêneros. No grupo do gênero feminino, a menor AF média foi de $17,10 \mathrm{~mm}^{2}$, enquanto, no grupo do gênero masculino, a menor AF média encontrada foi de $14,74 \mathrm{~mm}^{2}$. Os maiores valores médios da AF foram encontrados no nível vertebral cervical de C3 no grupo do gênero feminino e de C6 no grupo do gênero masculino. Enquanto, no gênero feminino, a maior AF média foi de $27,55 \mathrm{~mm}^{2}$, no gênero masculino, o maior valor foi de 29,48 $\mathrm{mm}^{2}$.

Tabela 6 - Médias \pm DP da área dos forames transversos (AFs) para cada nível e para cada lado.

\begin{tabular}{|c|c|c|c|c|c|c|c|c|c|c|}
\hline & \multicolumn{5}{|c|}{ Esquerda $\left(\mathrm{mm}^{2} \pm \mathrm{DP}\right)$} & \multicolumn{5}{|c|}{ Direita $\left(\mathrm{mm}^{2} \pm \mathrm{DP}\right)$} \\
\hline & $\mathbf{C 3}$ & $\mathrm{C4}$ & C5 & C6 & C7 & $\mathbf{C 3}$ & C4 & C5 & C6 & C7 \\
\hline $\mathbf{F}$ & $27,55 \pm 4,7$ & $26,26 \pm 4,8$ & $24,85 \pm 5,4$ & $26,94 \pm 9,3$ & $17,10 \pm 7,5$ & $25,52 \pm 4,2$ & $25,07 \pm 7,3$ & $23,48 \pm 6,4$ & $23,92 \pm 8,2$ & $18,60 \pm 8,9$ \\
\hline M & $26,71 \pm 5,6$ & $27,18 \pm 6,0$ & $28,14 \pm 7,2$ & $29,48 \pm 8,9$ & $14,74 \pm 8,5$ & $23,60 \pm 4,4$ & $23,55 \pm 5,3$ & $25,49 \pm 7,3$ & $25,48 \pm 8,6$ & $14,81 \pm 8,1$ \\
\hline
\end{tabular}

Não percebemos uma tendência à diminuição ou ao aumento dos valores médios da $\mathrm{AF}$ conforme migramos de proximal para distal na coluna vertebral cervical (Tabela 6).

Evidenciamos diferença estatística quando comparamos os valores médios da $\mathrm{AF}$ encontrados entre os lados direito e esquerdo nos níveis de C3 a C6 nos pacientes do gênero masculino, sendo que os valores foram maiores do lado esquerdo $(\mathrm{P}<0,05)$ (Gráfico 1). Nos pacientes do gênero feminino, evidenciamos diferença estatística entre os lados, somente no nível de $\mathrm{C} 3$, sendo o lado esquerdo maior $(\mathrm{P}<0,05)$ (Gráfico 2). 
Gráfico 1 - Comparação das médias das AFs entre os lados para cada nível no gênero masculino.

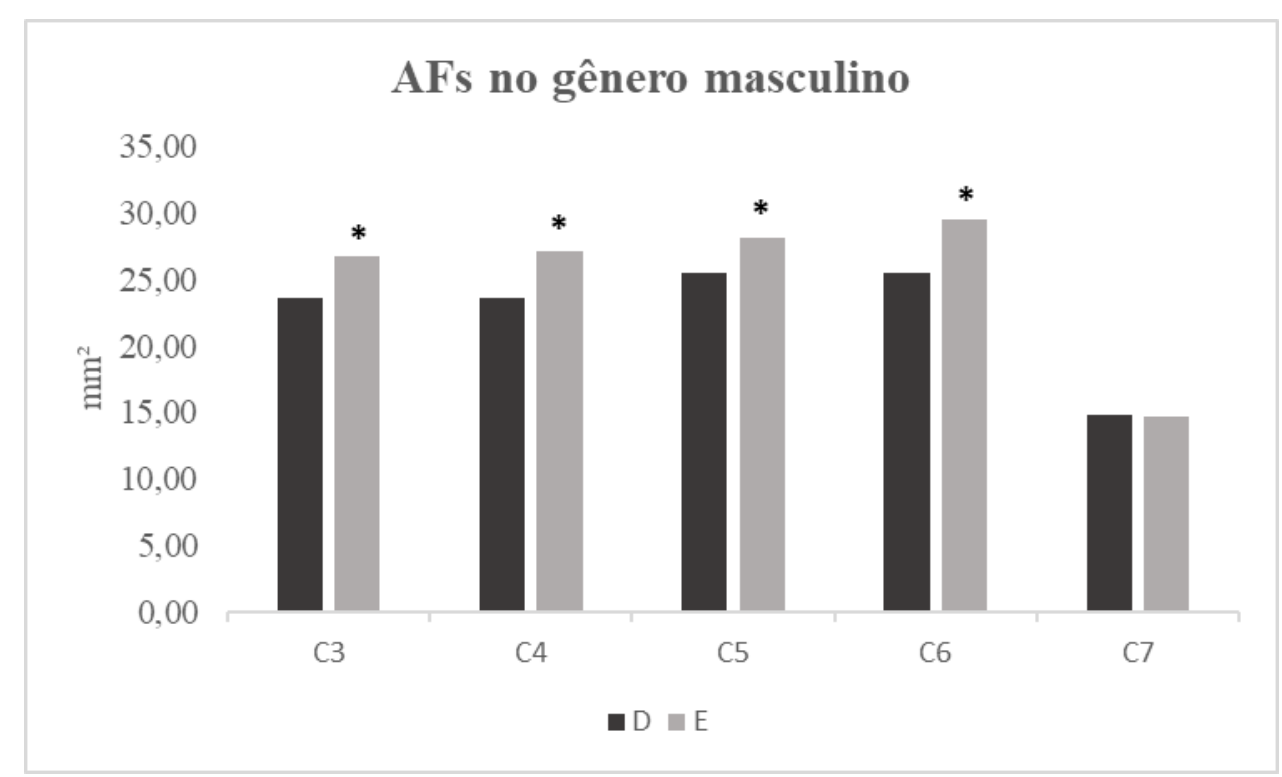

D - Direito; E - Esquerdo; * - Valor $p<0,05 ; \mathbf{~ m m}^{2}$ - milímetro quadrado.

Gráfico 2 - Comparação das médias das AFs entre os lados para cada nível no gênero feminino.

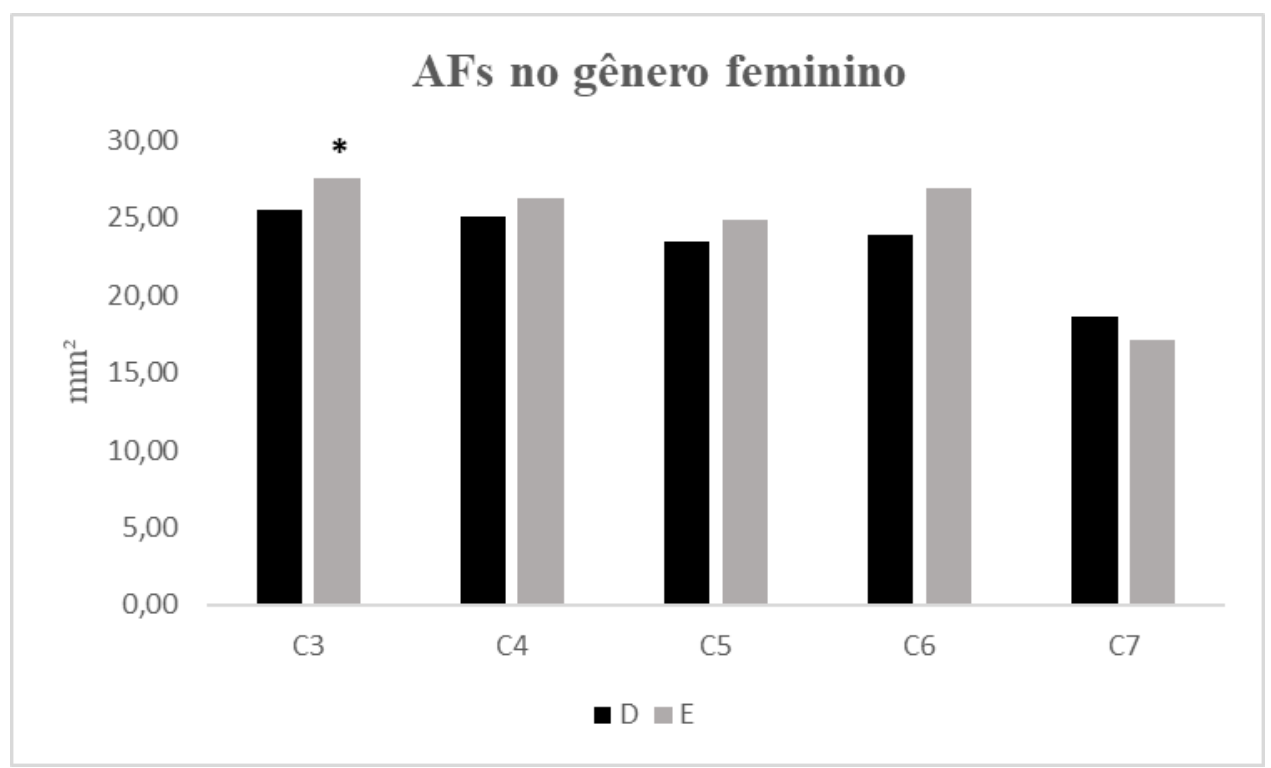

Legenda: D - Direito; E - Esquerdo feminino; * Valor $p<0,05 ; \mathbf{m m}^{\mathbf{2}}$ - milímetro quadrado.

Os valores obtidos das avaliações das AFs por nível, lado e gênero estão apresentados na tabela 7. Quando comparamos os valores obtidos de AF entre os gêneros, notamos diferença estatística no nível C3 e C7 do lado direito, sendo maior no gênero feminino $(\mathrm{P}<0,05)$. Por outro 
lado, evidenciamos diferença estatística no nível C5 do lado esquerdo, sendo maior no gênero masculino $(\mathrm{P}<0,05)$. Nas demais comparações, não foi evidenciada diferença estatisticamente significativa (Gráfico 3).

Tabela 7 - Resumo da Análise descritiva das AFs para cada nível em mm².

\begin{tabular}{|c|c|c|c|c|c|c|c|c|}
\hline Gênero & Lado & Níveis & $\mathbf{n}$ & Média & DP & Mínimo & Mediana & Máximo \\
\hline \multirow{10}{*}{$\mathbf{F}$} & \multirow{5}{*}{ D } & C3 & 60 & 25.52 & 4.18 & 16.12 & 24.95 & 33.91 \\
\hline & & $\mathrm{C} 4$ & 60 & 25.07 & 7.27 & 11.50 & 24.68 & 60.99 \\
\hline & & C5 & 60 & 23.48 & 6.37 & 11.83 & 22.25 & 36.69 \\
\hline & & C6 & 57 & 23.92 & 8.21 & 4.60 & 23.61 & 42.57 \\
\hline & & $\mathrm{C} 7$ & 48 & 18.60 & 8.87 & 4.93 & 18.09 & 48.07 \\
\hline & \multirow{5}{*}{$\mathbf{E}$} & C3 & 60 & 27.55 & 4.74 & 15.00 & 27.03 & 38.14 \\
\hline & & $\mathrm{C} 4$ & 60 & 26.26 & 4.80 & 17.70 & 25.91 & 37.39 \\
\hline & & $\mathrm{C} 5$ & 60 & 24.85 & 5.42 & 15.93 & 24.40 & 36.80 \\
\hline & & C6 & 59 & 26.94 & 9.28 & 3.16 & 28.10 & 43.08 \\
\hline & & $\mathrm{C} 7$ & 48 & 17.10 & 7.52 & 4.48 & 16.28 & 39.43 \\
\hline \multirow{10}{*}{$\mathbf{M}$} & \multirow{5}{*}{ D } & C3 & 60 & 23.60 & 4.42 & 11.82 & 23.60 & 34.40 \\
\hline & & $\mathrm{C} 4$ & 60 & 23.55 & 5.33 & 6.98 & 24.22 & 32.10 \\
\hline & & C5 & 60 & 25.49 & 7.30 & 7.36 & 25.61 & 44.70 \\
\hline & & C6 & 57 & 25.48 & 8.57 & 7.30 & 25.43 & 43.64 \\
\hline & & $\mathrm{C} 7$ & 46 & 14.81 & 8.05 & 4.36 & 12.71 & 43.10 \\
\hline & \multirow{5}{*}{$\mathbf{E}$} & $\mathrm{C} 3$ & 60 & 26.71 & 5.57 & 13.92 & 25.81 & 40.19 \\
\hline & & $\mathrm{C} 4$ & 60 & 27.18 & 5.98 & 13.74 & 27.64 & 40.69 \\
\hline & & C5 & 59 & 28.14 & 7.15 & 7.40 & 28.81 & 42.64 \\
\hline & & C6 & 57 & 29.48 & 8.86 & 6.80 & 28.99 & 51.20 \\
\hline & & $\mathrm{C} 7$ & 50 & 14.74 & 8.54 & 4.25 & 13.15 & 42.00 \\
\hline
\end{tabular}

F - feminino; M - masculino; D - Direito; E - Esquerdo; DP - Desvio padrão. 
Gráfico 3 - Comparação das médias das AFs entre os gêneros para cada nível por lado.

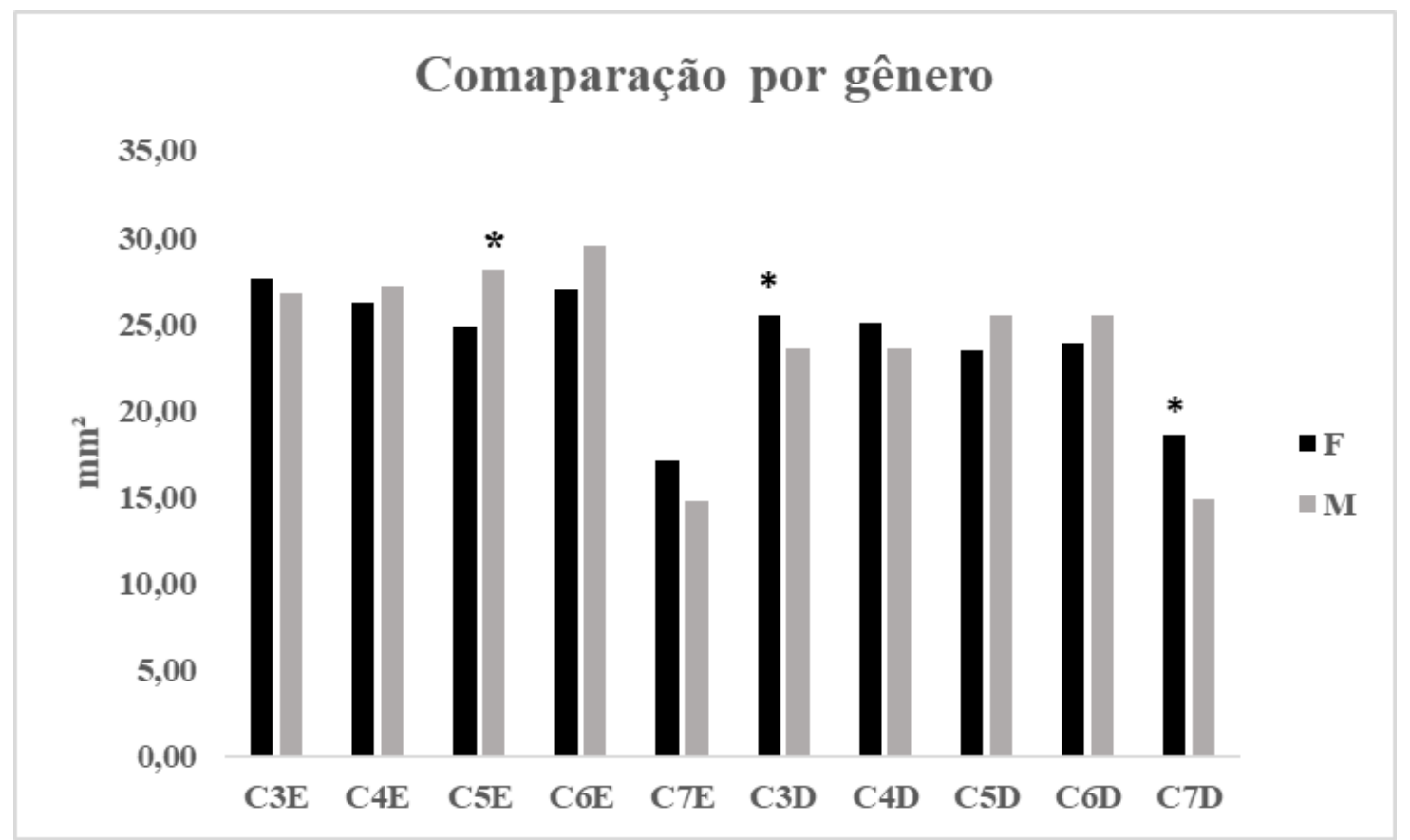

F - feminino; $\mathbf{M}$ - masculino; $\mathbf{E}$ - Esquerdo; D - Direito; $\mathbf{m m}^{\mathbf{2}}$ - Milímetros quadrados;

* - Valor $p<0,05$.

\subsection{Grupos por faixa etária}

Ao dividirmos os pacientes em três grupos, de acordo com a faixa etária (grupo 1, os pacientes de 18 a 24 anos; o grupo 2, os pacientes de 41 a 60 anos, e o grupo 3, os pacientes acima de 60 anos), notamos uma tendência ao aumento dos valores médios da AF conforme o avanço da faixa etária do grupo estudado (Gráfico 4). Entretanto, observamos diferença estatisticamente significativa apenas nos níveis C4 e C6, sendo que os valores de p estão apresentados na tabela 8 . 
Gráfico 4 - Comparação das médias das AFs entre os grupos por faixa etária para cada nível.

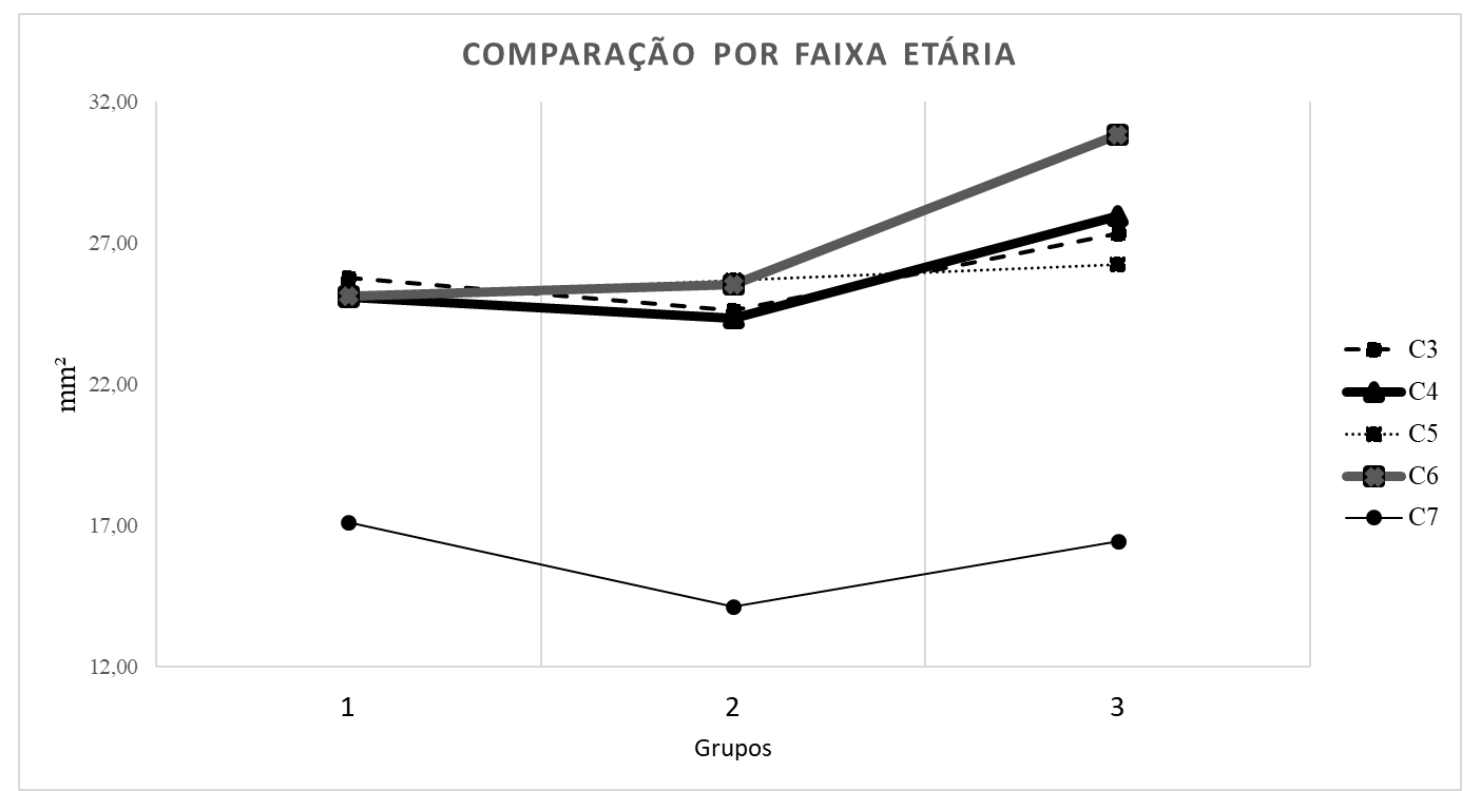

Grupo 1 (18 a 40 anos); Grupo 2 (41 a 60 anos); Grupo 3 (> 60 anos); mm² - Milímetros quadrados.

Tabela 8 - Valor- $p$ das comparações das AFs entre os grupos por faixa etária para cada nível e para cada lado.

\begin{tabular}{ccccccc}
\hline Lado Comparações & C3 & C4 & C5 & C6 & C7 \\
\hline \multirow{2}{*}{ D } & $\mathbf{1}$ - $\mathbf{2}$ & 0,923 & 0,231 & 0,224 & 0,785 & 0,199 \\
& $\mathbf{1}-\mathbf{3}$ & 0,065 & $\mathbf{0 , 0 1 0}$ & 0,245 & $\mathbf{0 , 0 1 1}$ & 0,629 \\
& $\mathbf{2}-\mathbf{3}$ & 0,134 & 0,211 & 0,990 & $\mathbf{0 , 0 4 4}$ & 0,511 \\
\hline & $\mathbf{1}-\mathbf{2}$ & 0,129 & $\mathbf{0 , 0 4 7}$ & 0,127 & 0,731 & 0,344 \\
$\mathbf{E}$ & $\mathbf{1}-\mathbf{3}$ & 0,658 & 0,374 & 0,446 & $\mathbf{0 , 0 0 3}$ & 0,969 \\
& $\mathbf{2}-\mathbf{3}$ & 0,109 & $\mathbf{0 , 0 1 9}$ & 0,060 & $\mathbf{0 , 0 2 4}$ & 0,459 \\
\hline
\end{tabular}

E - Esquerdo; D - Direito; 1 (Grupo de 18 a 40 anos); 2 (Grupo de 41 a 60 anos); 3 (Grupo > 60 anos).

\subsection{Confiabilidade interobservador}

A confiabilidade interobservador encontrada foi boa para as medidas tomográficas referentes a $\mathrm{AF}$ de $\mathrm{C} 3(0,78)$; muito boa para $\mathrm{C} 4(0,85)$; muito boa para $\mathrm{C} 5(0,86)$; muito boa 
para C6 $(0,89)$ e muito boa para C7 $(0,82)$. Os valores de confiabilidade interobservador estão demonstrados na Tabela 9.

Tabela 9 - Coeficiente de correlação intraclasse (CCI) e o intervalo de confiança (IC) de 95\% para a análise de concordância entre os dois avaliadores.

\begin{tabular}{ccc}
\hline Nível & CCI & IC 95\% \\
\hline C3 & 0,786 & $0,663-0,860$ \\
C4 & 0,854 & $0,769-0,905$ \\
C5 & 0,859 & $0,759-0,912$ \\
C6 & 0,898 & $0,851-0,929$ \\
C7 & 0,824 & $0,728-0,887$ \\
\hline
\end{tabular}

\subsection{Variações anatômicas}

Quanto às variações anatômicas dos FTs (AS, DU, SU, HS, AG e presença de CC), identificamos sua presença em 187 vértebras (62,3\%) de 300 avaliadas, sendo que 57 indivíduos (95\%) do total da amostra apresentaram pelo menos uma alteração morfológica e, em 25 indivíduos (42\%), identificamos mais de três variações anatômicas. Além disso, em 27,6\% (34/123) das vértebras, a variação anatômica foi bilateral e, em 72,4\% (89/123), unilateral, com o predomínio do lado direito $(45,5 \%)$ ocorrendo em 56 vértebras. Os dados referentes às variações anatômicas estão apresentados na tabela 10. 
Tabela 10 - Registro de frequência e proporções das variações anatômicas nas vértebras por nível.

\begin{tabular}{|c|c|c|c|c|c|c|}
\hline $\begin{array}{c}\text { Variaçãa } \\
\text { Anatômica }\end{array}$ & $\begin{array}{c}\text { C3 } \\
\text { Freq. }(\%)\end{array}$ & $\begin{array}{c}\text { C4 } \\
\text { Freq. }(\%)\end{array}$ & $\begin{array}{c}\text { C5 } \\
\text { Freq. }(\%)\end{array}$ & $\begin{array}{c}\text { C6 } \\
\text { Freq. (\%) }\end{array}$ & $\begin{array}{c}\text { C7 } \\
\text { Freq. }(\%)\end{array}$ & $\begin{array}{c}\text { Total } \\
\text { Freq. }(\%)\end{array}$ \\
\hline Assimetria & $9(3,0)$ & $9(3,0)$ & $12(4,0)$ & $17(5,7)$ & $17(5,7)$ & $64(21,3)$ \\
\hline Duplicação & & $5(1,7)$ & $16(5,3)$ & $26(8,7)$ & $4(1,3)$ & $51(17,0)$ \\
\hline Sulco & $1(0,3)$ & $5(1,7)$ & $11(3,7)$ & $18(6,0)$ & $4(1,3)$ & $39(13,0)$ \\
\hline Hipoplasia & & & & $6(2,0)$ & $18(6,0)$ & $24(8,0)$ \\
\hline Agenesia & & & & & $5(1,7)$ & $5(1,7)$ \\
\hline Incompleto & & $1(0,3)$ & $1(0,3)$ & $1(0,3)$ & & $3(1,0)$ \\
\hline Costela & & & & & $1(0,3)$ & $1(0,3)$ \\
\hline Total & $10(3,3)$ & $20(6,7)$ & $40(13,3)$ & $68(22,7)$ & $49(16,3)$ & $187(62,3)$ \\
\hline
\end{tabular}

Freq. - Frequência; \% - Porcentagem.

AS foi a variação anatômica mais encontrada em nossa amostra, identificada em 35 indivíduos (58,3\%) (Tabela 10 -11 e Figura 12).

Tabela 11 - Registro de frequência e proporções das vértebras com AS dos forames transversos por gênero e por nível.

\begin{tabular}{|c|c|c|c|c|c|c|c|c|c|c|c|}
\hline & \multicolumn{5}{|c|}{ E - Freq. (\%) } & \multicolumn{5}{|c|}{ D - Freq. (\%) } & \multirow{2}{*}{ TOTAL } \\
\hline & $\mathrm{C} 3$ & C4 & C5 & C6 & C7 & $\mathrm{C3}$ & C4 & C5 & C6 & C7 & \\
\hline M & $4(6,3)$ & $5(7,8)$ & $4(6,3)$ & $7(10,9)$ & $3(4,7)$ & $1(1,6)$ & $1(1,6)$ & $1(1,6)$ & $1(1,6)$ & $8(12,5)$ & $35(54,7)$ \\
\hline $\mathbf{F}$ & $3(4,7)$ & $2(3,1)$ & $6(9,4)$ & $6(9,4)$ & $3(4,7)$ & $1(1,6)$ & $1(1,6)$ & $1(1,6)$ & $3(4,7)$ & $3(4,7)$ & $29(45,3)$ \\
\hline Total & $7(10,9)$ & $7(10,9)$ & $10(15,6)$ & $13(20,3)$ & $6(9,4)$ & $2(3,1)$ & $2(3,1)$ & $2(3,1)$ & $4(6,3)$ & $11(17,2)$ & $64(100,0)$ \\
\hline
\end{tabular}

E - esquerdo; D - direito; Freq. - Frequência; \% - Porcentagem; M - masculino; F - feminino. 
Figura 12 - Tomografia em corte axial ilustrando a AS com o FT esquerdo maior.

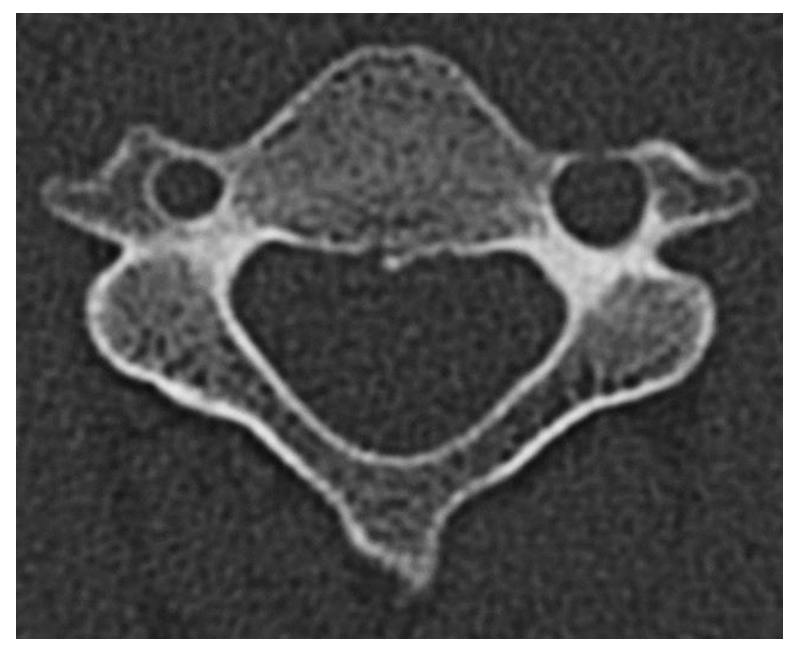

A DU foi a segunda variação anatômica mais observada em nossa amostra, identificada em 32 indivíduos $(53,3 \%)$. Essa variação foi representada por 17\% (51/300) das vértebras estudadas e $11 \%$ (66/600) dos forames. O nível mais acometido pela DU foi o C6, no qual identificamos 33 forames duplicados nas imagens tomográficas estudadas (Tabela 12 e Figura 13).

Tabela 12 - Frequências e proporções das variações anatômicas nos FTs por nível.

\begin{tabular}{|c|c|c|c|c|c|c|}
\hline & $\begin{array}{c}\text { C3 } \\
\text { Freq. }(\%) \\
\end{array}$ & $\begin{array}{c}\text { C4 } \\
\text { Freq. }(\%)\end{array}$ & $\begin{array}{c}\text { C5 } \\
\text { Freq. (\%) }\end{array}$ & $\begin{array}{c}\text { C6 } \\
\text { Freq. }(\%)\end{array}$ & $\begin{array}{c}\text { C7 } \\
\text { Freq. }(\%) \\
\end{array}$ & $\begin{array}{c}\text { Total } \\
\text { Freq. }(\%)\end{array}$ \\
\hline Duplicação & & $5(0,8 \%)$ & $23(3,8 \%)$ & $33(5,5 \%)$ & $5(0,8 \%)$ & $66(11,0)$ \\
\hline Sulco & $1(0,2 \%)$ & $5(0,8 \%)$ & $14(2,3 \%)$ & $23(3,8 \%)$ & $5(0,8 \%)$ & $48(8,0)$ \\
\hline Hipoplasia & & & & $7(1,2 \%)$ & $22(3,7 \%)$ & $29(4,9)$ \\
\hline Agenesia & & & & & $9(1,5 \%)$ & $9(1,5)$ \\
\hline Incompletao & & $1(0,2 \%)$ & $1(0,2 \%)$ & $1(0,2 \%)$ & & $3(0,6)$ \\
\hline Costela & & & & & $2(0,3 \%)$ & $2(0,3)$ \\
\hline Total & $1(0,2 \%)$ & $11(1,8 \%)$ & $38(6,3 \%)$ & $64(10,7 \%)$ & $43(7,2 \%)$ & $157(26,2)$ \\
\hline
\end{tabular}

Freq. - Frequência; \% - Porcentagem. 
Figura 13 - Tomografia em corte axial ilustrando DU unilateral (A) e DU bilateral (B).
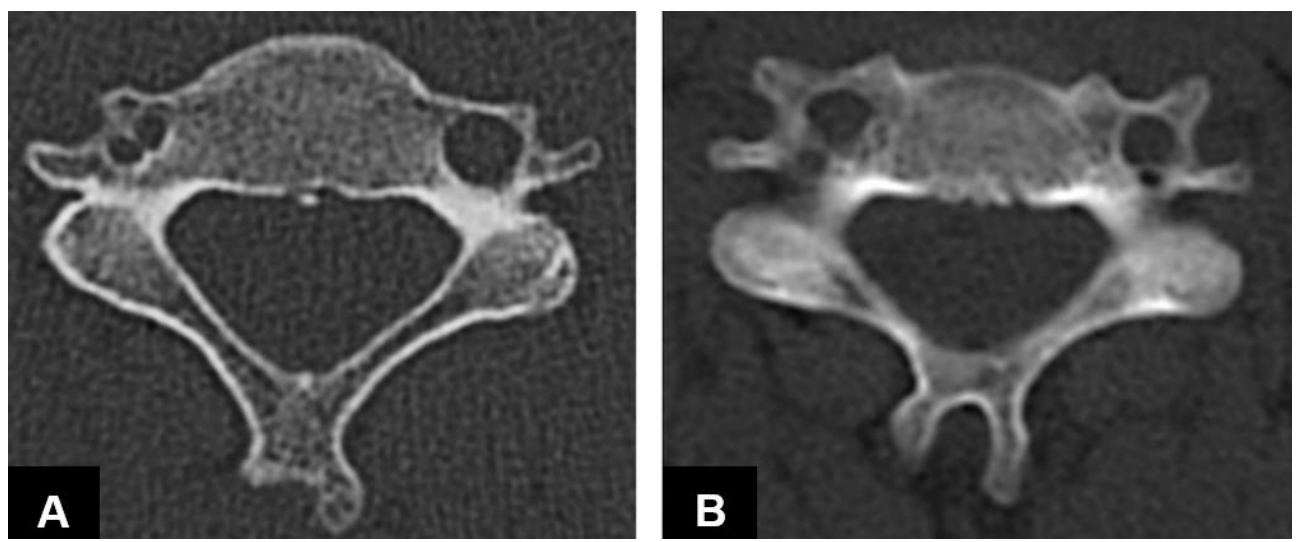

A terceira variação mais observada foi a SU em um total de 25 indivíduos $(41,7 \%)$, sendo 39 das vértebras (13\%) e 48 forames (8\%). Assim como a DU, o nível C6 foi o mais acometido pelo sulco com 23 forames (3,8\%) (Tabela 10 e 12) (Figura 14).

Figura 14 - Tomografia em corte axial ilustrando SU bilateral

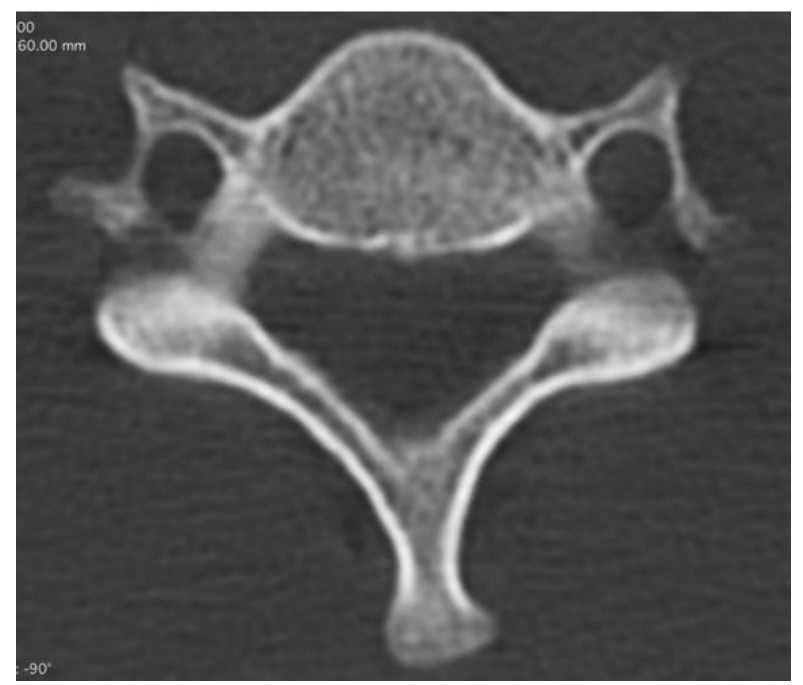

A HS foi observada em 22 indivíduos da amostra (36,7\%), tendo sido identificada apenas nos níveis C6 e C7 (Tabela 10 e Figura 15). Quanto às demais variações anatômicas, identificamos a AG em 5 indivíduos (8,3\%), o FI em 3 indivíduos (5\%) e a CC em 1 indivíduo $(1,7 \%)$ totalizando 9 indivíduos com essas variações (Figura 16). 
Figura 15 - Tomografia em corte axial ilustrando HS unilateral (A) e bilateral (B).
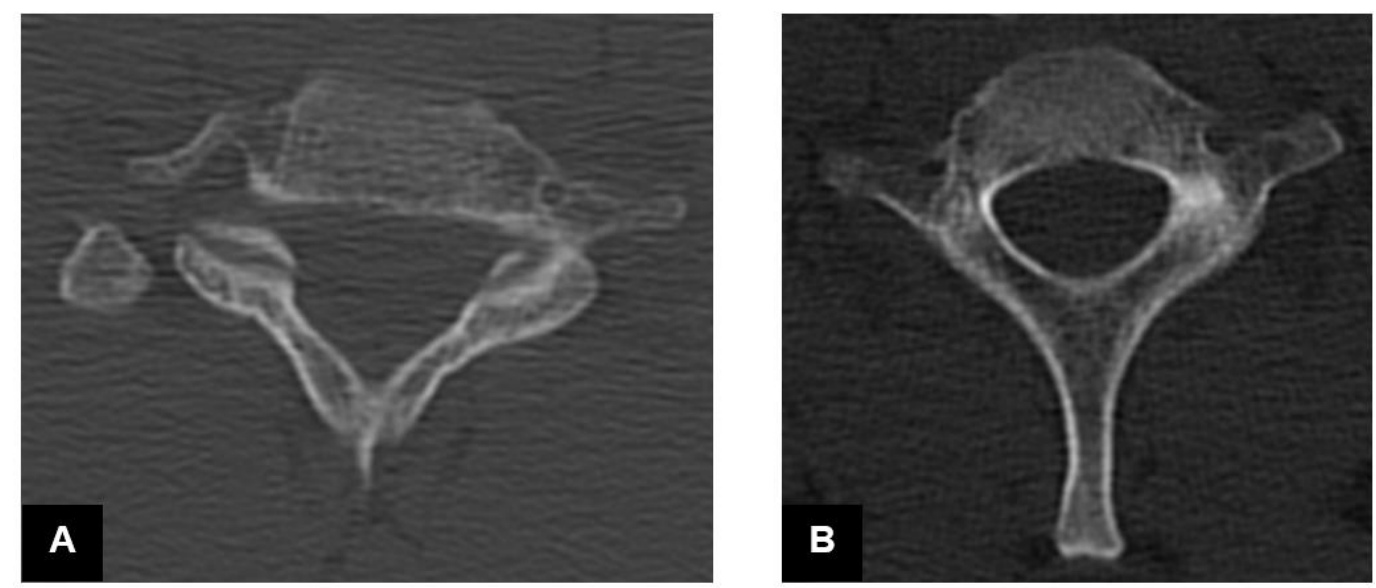

Figura 16 - Tomografia em corte axial ilustrando AG à esquerda (A), FI à esquerda (B) e CC bilateral (C).
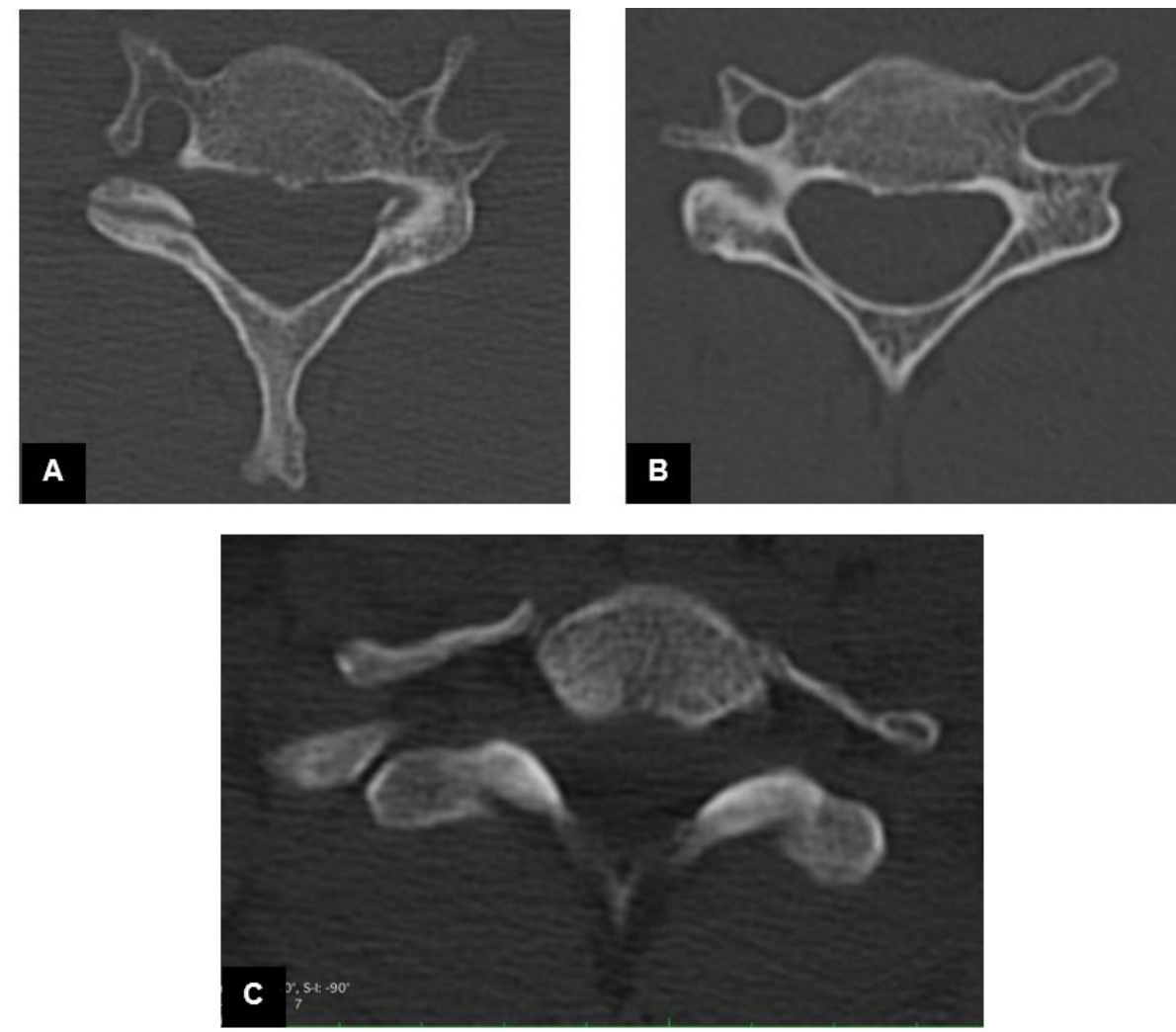

Ao analisarmos a confiabilidade interobservador das variações anatômicas dos FTs, identificamos que, no nível C4, a confiabilidade foi aceitável do lado esquerdo $(0,38)$ e considerável do lado direito $(0,67)$; no nível C5, foi considerável em ambos os lados $(0,65$ e 
0,67); no nível C6, foi considerável do lado esquerdo $(0,68)$ e moderada do lado direito $(0,50)$; no nível C7, foi aceitável nos dois lados (0,21 e 0,39). 
DISCUSSÃO 


\section{DISCUSSÃO}

A partir dos resultados encontrados neste estudo, identificamos as características da anatomia do FT da coluna cervical baixa (C3 - C7) em uma amostra da população brasileira. A importância da definição adequada da morfometria do FT reside no fato de técnicas cirúrgicas colocarem em risco as estruturas localizadas no interior do forame. Logo, esses parâmetros devem ser observados previamente à realização de procedimentos cirúrgicos que visam abordar a coluna cervical. Estudos prévios acerca das dimensões do FT cervical incluíram populações europeias, asiáticas e americanas (JAÉN E., 1975; MOLINET GUERRA; ROBLES FUENTES; ROA, 2017; SUREKA et al., 2018; ZIBIS et al., 2018), no entanto, não incluíram a população brasileira. Assim como muitas outras diferenças anatômicas morfométricas encontradas em diferentes raças e etnias, acreditamos que os dados obtidos da literatura devam ser utilizados com cautela, já que podem não ser aplicados universalmente.

Ao revisarmos a literatura, identificamos, principalmente, duas técnicas utilizadas para medir os FTs da coluna cervical. A primeira é realizada com um paquímetro diretamente na peça anatômica e a segunda, indiretamente, por meio de programas (software) para a avaliação de imagens tomográficas.

Essas imagens, além de representarem um aumento de dez vezes a resolução de contraste, quando comparadas com radiografias convencionais, oferecem cortes anatômicos em diferentes planos da estrutura em estudo sem superposição de outras imagens. No entanto, Okuyama et al. (1994) em um estudo anatômico, comparando as duas técnicas, evidenciaram que os resultados das medidas obtidas com paquímetro de pedículos da coluna lombar de espécimes de cadáver foram significativamente menores, nos níveis L3-L4 e L5, do que as medidas obtidas por meio de TC. Os autores atribuíram essa diferença à divergência no ângulo do eixo dos pedículos, responsável pelo fato de a medida determinada pelo corte axial da TC não corresponder à medida real realizada diretamente com paquímetro.

Por outro lado, acreditamos que as medidas realizadas com paquímetro possam ter dificuldades pela irregularidade das superfícies de estruturas anatômicas circunjacentes ao FT. Dessa forma, consideramos que a TC, apesar da desvantagem mencionada, facilita a análise da anatomia óssea, quando comparada com estudos em espécimes de cadáver. A detecção de diferença de contrastes mínimos produz maior detalhe das estruturas ósseas. Além disso, os 
avanços na criação de ferramentas nos programas que fazem a avaliação das imagens tomográficas tornam as medidas anatômicas de estruturas ósseas mais viáveis e precisas. Comparando esse dado, estudos mostraram níveis altos de confiabilidade e reprodutibilidade das medidas por essa metodologia (CAGNIE et al., 2005; KIM et al., 2012; MOLINET GUERRA; ROBLES FUENTES; ROA, 2017; SUREKA et al., 2018; ZIBIS et al., 2018, 2016). Assim, o método de escolha utilizado em nosso estudo foi a análise de imagens obtidas por meio de TC.

No estudo da anatomia do FT, Taitz, Nathan e Arensburg (1978) demonstraram a importância das medidas dos diâmetros anteroposterior e lateral. Para a determinação do formato do FT, avaliaram 480 FT (C1 a C7) de cadáveres e mediram seus diâmetros utilizando um paquímetro. Seguidamente, a identificação do maior diâmetro e a orientação de seu eixo permitiram que os autores classificassem os forames em 5 tipos: Circular (tipo 1), elíptico com DAP maior (tipo 2), elíptico com DL maior (tipo 3), elíptico com o eixo do maior diâmetro oblíquo, de direita para esquerda (tipo 4) e elíptico com o eixo do maior diâmetro oblíquo, de esquerda para direita (tipo 5). Para os autores, o tipo 3, cujo DL é maior, foi o mais frequente nos forames dos níveis C3, C4 e C5. Por não acreditarmos na importância dessa classificação para o objetivo proposto, optamos por não realizá-la em nosso estudo.

Gupta et al. (2014), reproduzindo os tipos de forame da série de Taitz, identificaram também, como o mais frequente, o tipo 3 (41\%) nos níveis C3, C4 e C5. A maior média do DL foi de 4,83 $\mathrm{mm} \pm 1,03$, no nível de $\mathrm{C} 6$ à direita, e de $5,5 \mathrm{~mm} \pm 0,9$, no nível de $\mathrm{C} 5$ à esquerda, sendo que ambos resultados foram obtidos de 160 forames estudados em imagens tomográficas de uma parte da coluna cervical baixa (C3 a C6). Em nosso estudo, observamos que o DL foi significativamente maior, quando comparado com o DAP ( $p<0,05)$, e ambos diâmetros foram maiores à esquerda, com diferença estatisticamente significativa nos níveis de C3 a C5 (p<0,05) e sem diferença estatisticamente significativa nos níveis C6 e C7 (P>0,05). Ao avaliarmos a coluna cervical baixa (C3 a C7), identificamos que o maior DL médio encontrado foi de 6,43 $\mathrm{mm} \pm 0,8$ à esquerda e $6,12 \mathrm{~mm} \pm 0,7$ à direita, ambos no nível de $\mathrm{C} 3$. Ao compararmos os resultados com o trabalho de Gupta, observamos que o nosso maior DL difere quanto ao nível identificado. No entanto, coincidimos com os dados de Metin Tellioglu et al. (2018), que estudaram 1.974 FT de imagens tomográficas e identificaram nelas também o nível de C3 com uma média de 5,93 $\mathrm{mm} \pm 1,0$ à esquerda e 5,86 $\mathrm{mm} \pm 1,01$ à direita. No mesmo estudo, os autores observaram a medida da menor média do DL de 3,58 $\mathrm{mm} \pm 1,25$ à direita e 3,60 mm $\pm 1,32$ à esquerda, ambos em C7. Já o nosso menor valor encontrado foi de 4,53 $\mathrm{mm} \pm 1,3 \mathrm{em}$ ambos os 
lados, confirmando o nível C7 como o mais frequente, assim como em outros trabalhos apresentados na literatura (CAGNIE et al., 2005; DEĞIRMENCI; YILMAZ, 2013; METIN TELLIOGLU et al., 2018; TAITZ; NATHAN; ARENSBURG, 1978).

Observamos que houve maior similitude entre os estudos recentes, ao identificar os níveis com maior ou menor DAP, sendo em C6 o maior DAP encontrado e, em C7, o menor (GUPTA et al., 2014; METIN TELLIOGLU et al., 2018; ZIBIS et al., 2018). Por outro lado, não observamos diferenças nas médias obtidas quando comparamos estudos em cadáver, em que a medida era realizada com paquímetros, com os realizados em pacientes, nos quais a medida era realizada em cortes axiais de imagens tomográficas por meio de um programa computadorizado que possui ferramentas para a interpretação das imagens, tal como em nosso estudo. No entanto, no grupo de estudos realizados em imagens tomográficas, Gupta et al. (2014) obtiveram uma média baixa para a medida do maior DAP 3,73 $\mathrm{mm} \pm 1,22$ à direita e

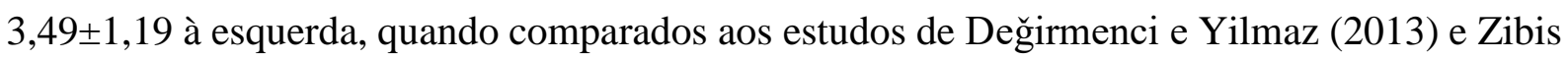
et al. (2016) (realizados em cadáver), que obtiveram em média 5,7 $\mathrm{mm}$ em ambos forames, esquerda e direita. Em novo estudo, Zibis et al. (2018), realizado desta vez em pacientes, em 700 forames da coluna cervical (C1 a C7) de imagens de Angiotomografía, identificaram a maior média do DAP em C6, sendo 6,07 mm à direita e 6,27 mm à esquerda. Em nosso estudo, observamos o maior DAP médio de $6,05 \mathrm{~mm}$ no gênero masculino, enquanto, para o grupo do gênero feminino, o maior DAP médio foi de 5,56 mm ambos no nível de C6. O menor DAP médio foi encontrado no nível C7 em ambos os gêneros. Nos pacientes do gênero feminino, o menor valor encontrado foi de $4,31 \mathrm{~mm}$, enquanto no gênero masculino o menor valor encontrado foi de $3,88 \mathrm{~mm}$. Não foi possível perceber uma tendência ao aumento ou à diminuição do valor do DAP médio, conforme avançamos de proximal para distal na coluna cervical da mesma maneira como foi observada no DL, em que identificamos uma tendência à diminuição do valor do DL médio à medida que avançávamos de proximal para distal na coluna cervical. Observamos também que o valor do DAP médio encontrado foi maior no lado esquerdo, quando comparado ao lado direito nos níveis de C3 a C6 $(\mathrm{P}<0,05)$, porém sem diferença estatisticamente significativa no nível C7 (P>0,05).

Comparado ao número de estudos que incluíram a avaliação do DL e DAP, um número menor foi realizado acerca da AF da coluna cervical. Entre eles, destaca-se Bruneau et al. (2006) que obtiveram a AF aplicando a fórmula geométrica $(\mathrm{A}=\pi * \mathrm{M} / 2 * \mathrm{~m} / 2)$ para elipses (forma oval regular), baseada em dois eixos principais do forame, maior e menor. No entanto, observamos, em nosso estudo, que os forames não possuem forma regular constante, já que as 
irregularidades na sua borda podem não expressar um resultado real da sua área. Atualmente, os programas de processamento de imagens possuem uma ferramenta para a mensuração da área em superfícies irregulares com excelente reprodutibilidade e confiabilidade (KIM et al., 2012). Apesar da necessidade de uma maior precisão, ao desenhar o forame no programa (OsiriX Pixmeo, 7.0.2) de processamento de imagem utilizado para a obtenção da área, consideramos que a variável área oferece um parâmetro mais real na interpretação da relação do FT com seu conteúdo.

Para a avaliação da AFs da coluna cervical baixa (C3-C7), selecionamos os cortes axiais de imagens tomográficas que permitiram a visualização mais precisa da borda interna dos forames vertebrais, utilizando a análise de dois planos (sagital e axial). Apesar de poucos trabalhos terem utilizado essa técnica, identificamos, no nosso estudo, assim como na série de Kim et al. (2012), forte confiabilidade entre os observadores ao obter os resultados das medidas das AFs, tendo, no nosso estudo, confiabilidade boa para o nível C3 $(0,78)$ e muito boa para os níveis de C4 a C7 (valores > 0,81).

Estudos da coluna cervical realizados em imagens de Ressonância Magnética e TC com contraste mostraram que existe correlação entre os diâmetros do FT e da AV. Kim et al. (2012) observaram que a área da $\mathrm{AV}$ é diretamente proporcional à $\mathrm{AF}$, pois, em seu estudo realizado em 208 pacientes submetidos a Angiotomografia, identificaram nos cortes axiais dos forames vertebrais dos níveis $\mathrm{C} 3$ a $\mathrm{C} 6$, forte correlação linear $\left(\mathrm{r}^{2}=0,58\right.$ à direita e $\mathrm{r}^{2}=0,62$ à esquerda) entre essas duas estruturas anatômicas. Além disso, as AFs e da AV aumentaram de cranial para caudal, sendo maior ao nível C6 (AV variou de 5,5 mm² em C3 a 11,3 mm² em C6 e o FT de $20,5 \mathrm{~mm}^{2}$ em C3 a 26,3 $\mathrm{mm}^{2}$ em C6). Outro detalhe observado diz respeito ao fato de que tanto a AV quanto o FT foram maiores à esquerda que à direita. Essas características da $\mathrm{AV}$, apresentadas no grupo de Kim, também foram observadas em outras séries (CAGNIE et al., 2005; GUPTA et al., 2014).

Além disso, Bruneau et al. (2006) afirmam que os FTs preenchidos pela AV são mais amplos, pois observaram que as medidas das áreas dos níveis abaixo do nível de entrada da AV são significativamente menores $(\mathrm{p}<0,05)$, variando de $6,28 \mathrm{~mm}^{2}$ em C5 a 7,06 mm² em C4 e C6, quando comparados com os FTs ocupados pela AV, que mostram valores médios de 23,75 $\mathrm{mm}^{2}$ em C4; de $23,85 \mathrm{~mm}^{2}$ em C5 e o maior de 24,97 mm² em C6. 
Em nosso estudo, identificamos uma média da AF que variou de 14,74 a 29,48 mm², sendo o maior valor médio de $27,55 \mathrm{~mm}^{2}$ no nível vertebral de $\mathrm{C} 3$ no grupo do gênero feminino

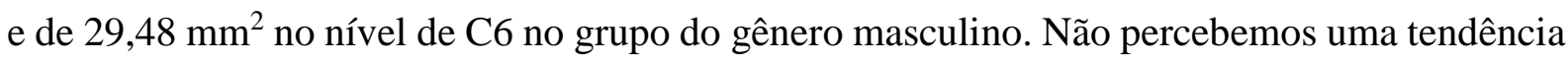
à diminuição ou ao aumento dos valores médios da $\mathrm{AF}$ conforme migramos de proximal para distal na coluna vertebral cervical. Ao compararmos os valores médios da AF entre os lados direito e esquerdo, observamos que os do lado esquerdo foram maiores, similar com os resultados apresentados por Kim et al. (2012). Além disso, identificamos diferença estatisticamente significativa somente nos níveis de C3 a C6 nos pacientes do gênero masculino e no nível de C3 nos pacientes do gênero feminino. Quando comparamos entre os gêneros, notamos que os valores obtidos da AF são maiores no gênero feminino nos níveis C3 e C7 do lado direito $(\mathrm{P}<0,05)$ e maiores no gênero masculino no nível de $\mathrm{C} 5$ do lado esquerdo $(\mathrm{P}<0,05)$. Estudos prévios, nos quais se comparou a AFs, não relataram diferença estatisticamente significativa quanto ao gênero (BRUNEAU et al., 2006; KIM et al., 2012).

Devemos enfatizar que as menores médias foram observadas ao nível de C7 em ambos os gêneros, o que pode ser explicado pelo fato de a AV não passar através do FT nesse nível na maior parte dos pacientes (AL-HABIB et al., 2018; CHOI; CHUNG; KIM, 2018; KAJIMOTO et al., 2007; TAITZ; NATHAN; ARENSBURG, 1978). No grupo do gênero feminino, a menor AF média foi de $17,10 \mathrm{~mm}^{2}$ (mínimo $=4,48 \mathrm{~mm}^{2}$ e máximo $=39,43 \mathrm{~mm}^{2}$ ) enquanto, no grupo do gênero masculino, a menor AF média encontrada foi de $14,74 \mathrm{~mm}^{2}\left(\right.$ mínimo $=4,25 \mathrm{~mm}^{2} \mathrm{e}$ máximo $=42,00 \mathrm{~mm}^{2}$ ), ambos resultados nos forames do lado esquerdo.

Os processos degenerativos alteram o alinhamento e a anatomia da coluna cervical cujas alterações incluem a perda da lordose fisiológica como resultado do estreitamento do disco intervertebral (LESTINI; WIESEL, 1989). Outras alterações gradualmente ocorrem ao nível das articulações zigoapofisárias, uncovertebrais e somáticas, podendo formar hipertrofias ósseas (osteófitos) e comprimir estruturas neurovasculares com manifestações clínicas já conhecidas (MALLA et al., 2018).

Vários estudos tentaram demonstrar a relação do FT com estruturas ósseas vizinhas capazes de modificar a sua anatomia (CAGNIE et al., 2005; MOLINET GUERRA; ROBLES FUENTES; ROA, 2017). A invasão ao FT por osteófitos provenientes dos processos unciformes e facetas articulares foram mais frequentes nos níveis mais baixos da coluna cervical (C5-C6) (TAITZ; NATHAN; ARENSBURG, 1978), possivelmente devido a estresse mecânico próprio desse segmento com maior mobilidade. Sabe-se que a prevalência das 
alterações degenerativas na coluna cervical aumenta com a idade, podendo chegar a $57 \%$ em maiores de 65 anos (MIKKELSEN; DUFF; DODGE, 1970). Dessa maneira, dividimos a nossa amostra em três grupos de acordo com a faixa etária para fins comparativos e observamos que existe uma tendência ao aumento dos valores médios da AF conforme o aumento da faixa etária do grupo estudado, encontrando os maiores valores no grupo 3 (pacientes acima de 60 anos) e os menores no grupo 1 (pacientes de 18 a 24 anos) nos níveis de C3 a C6. Entretanto, observamos diferença estatisticamente significativa apenas nos níveis C4 e C6 (P < 0,05).

Era de esperar que houvesse uma diminuição da AFs com o aumento da idade, como apresentado por Cagnie et al. (2005), que estudaram 111 vértebras de cadáveres de indivíduos que faleceram com idade entre 50 e 90 anos. Nessa análise, observaram o estreitamento do FT por osteófitos provenientes do processo unciforme em 48,13\%, de osteófitos da faceta articular superior em $29,91 \%$ e inferior em 30,84\%, sendo mais comum nos níveis mais baixos da coluna cervical C5-C6 (CAGNIE et al., 2005) e C7 (MOLINET GUERRA; ROBLES FUENTES; ROA, 2017). Por outro lado, Değirmenci e Yilmaz (2013) não identificaram diferenças nos diâmetros do FT entre os diferentes grupos etários (Grupo 1: 18 a 39 anos; Grupo 2:40 a 59 anos e grupo 3:60 a 85 anos), atribuindo esse fato ao total desenvolvimento esquelético da sua amostra.

Uma possível explicação para os nossos achados de aumento dos valores médios da AF conforme o aumento da faixa etária do grupo estudado ao invés de uma diminuição como nos estudos mencionados, seria o efeito do aumento do fluxo na AV observado em algumas condições que afetam o sistema cardiovascular. No entanto, essa hipótese carece de mais dados e precisa de estudos adicionais.

Com relação à variação anatômica, Taitz, Nathan e Arensburg (1978) acreditam que existe uma correlação entre as AVs e o FT, pois sugerem que os vasos vertebrais influenciam na formação deste. Dessa forma, pode-se admitir que variações na presença dos vasos vertebrais, ou em seu trajeto, podem se manifestar como variações do FT. Em nosso estudo, encontramos pelo menos uma variação anatômica em 95\% da amostra de um total de 60 indivíduos incluídos no estudo. Tal número é claramente superior aos resultados observados na literatura. Atribuímos essa diferença à inclusão de todas as variações anatômicas possíveis, já aqui descritas, enquanto alguns autores avaliaram somente parte delas. 
A AS foi a variação anatômica mais notada em nosso estudo, identificada em 35 indivíduos (58,3\%). De acordo com Değirmenci e Yilmaz (2013), a AS é a diferença notória do tamanho entre os forames do mesmo nível vertebral. Os autores identificaram 29 (3,2\%) vértebras assimétricas, sendo mais comum no nível C6 em 11,8\% dos indivíduos estudados. Embora tenham sido os primeiros a relatar essa condição como uma variação morfológica do FT, não designaram uma diferença quantitativa para a medida entre os forames. Em nosso estudo, para se especificar a AS entre os forames de um mesmo nível, determinou-se que a medida de sua área deve ser proporcionalmente 1,5 vezes maior que o outro. De acordo com essa proporção, detectamos 64 (21,3\%) vértebras assimétricas, sendo mais comuns nos níveis C6 e C7, cada uma com 17 vértebras assimétricas $(17 / 300=5,7 \%)$.

O forame duplicado foi descrito pela primeira vez por Meckel em 1912 (JAÉN E., 1975) e foi a segunda variação anatômica mais identificada em nosso estudo encontrada em 51 vértebras, representando $17 \%$ da amostra, similar ao resultado publicado na América pelo grupo de Molinet Guerra, Robles Fuentes e Roa (2017) e na Ásia pelo grupo de Gupta et al. (2014). Apesar da divergência nos resultados de DU na literatura, houve concordância com relação aos níveis mais acometidos, sendo C5 e C6 os mais recorrentes para a maioria dos pesquisadores (JAÉN E., 1975; KAYA et al., 2011; METIN TELLIOGLU et al., 2018; ZIBIS et al., 2018, 2016). Em nosso estudo, detectamos que em C6 está o nível mais acometido, com o $51 \%$ das vértebras com forame duplicado, seguido pelo nível C5, com $31 \%$.

No desenvolvimento embrionário, a AV é formada a partir da fusão de anastomoses longitudinais que ligam as artérias intersegmentares cervicais, ramos da aorta dorsal primitiva. Essas artérias regridem mais à frente no desenvolvimento embrionário (IONETE; OMOJOLA, 2006). Sim et al. (2001) descreveram que uma parte da aorta dorsal primitiva pode não regredir, juntamente com as artérias intersegmentares, o que deve ser a causa da DU e origem dupla da AV. Acreditamos que a ocorrência dessa duplicação arterial explique a presença relativamente frequente de forames duplicados.

A presença de um entalhe na borda interna do FT foi reportada pela primeira vez na literatura por Değirmenci e Yilmaz (2013) que o denominaram "sulco". Atribuíram sua formação não só à alteração de pressões nos vasos, causando modificações do FT, como também ao desenvolvimento de uma duplicação incompleta do FT, onde não há o septo ósseo que divide o forame, como acontece na DU. Os autores detectaram que 5,7\% (31 casos em C5 e 20 em C6) de 889 vértebras estudadas apresentavam FTs com um tipo de entalhe em sua 
porção anterior ou posterior. Em nossa amostra, a SU foi encontrada em 13\% das vértebras e foi visualizada em todos os níveis, com predomínio de C6 em 6\% (18/300) das vértebras. Como exposto anteriormente, os vasos vertebrais estariam envolvidos na formação dos FTs (EVANGELOPOULOS, 2012; TAITZ; NATHAN; ARENSBURG, 1978). Acredita-se que a pressão da AV também exerça papel importante na formação do FT, podendo até mesmo causar erosão óssea (KOVACS, 1955).

Taitz, Nathan e Arensburg (1978) encontraram 8 vértebras da sua amostra com forame muito pequeno, ainda que não tenham especificado sua medida. Değirmenci e Yilmaz (2013) descreveram o forame hipoplásico como aquele que apresenta um diâmetro menor a $2 \mathrm{~mm}$. De 93 vértebras $(10,4 \%)$ hipoplásicas, o nível C7 foi o mais frequente da sua amostra, com bilateralidade de $97 \%$ das vértebras com HS. Em nosso estudo, identificamos essa variação anatômica somente nos níveis C6 e C7, totalizando 8\% das vértebras estudadas e, dessas, $6 \%$ claramente mais comuns em C7. Os FTs hipoplásicos podem indicar um estreitamento dos vasos vertebrais cervicais ou sua ausência dentro do forame, podendo ter um trajeto adjacente à vértebra. Observamos que a HS é mais frequente nos níveis mais distais, sendo que a artéria, em vez de entrar no FT no nível de C6, entraria em níveis mais proximais (BRUNEAU et al., 2006), fato que corrobora os nossos achados.

Até hoje, a ausência de FT variou nas publicações de 1 a 4\%, principalmente no nível de C7 (JAÉN E., 1975; KIM et al., 2012; METIN TELLIOGLU et al., 2018; ZIBIS et al., 2018). Em nosso estudo, identificamos 5 vértebras com AG do forame transverso unicamente em C7, representando $1,7 \%$ de todas as vértebras analisadas. Entre as variações anatômicas menos observadas, identificamos a falta de fechamento do FT (forame incompleto). Das vértebras avaliadas por Zibis et al. (2018), 1,7\% apresentava o FI, característica também identificada em $1 \%$ das vértebras da nossa amostra.

As costelas cervicais são anomalias incomuns, com incidência variando de 0,05 a 3\% na literatura (BREWIN; HILL; ELLIS, 2009; CHANDAK; KUMAR, 2014; KOVACS, 1955; STEINER, 1943). Encontramos essa alteração em 1 caso, configurando o 0,3\% da população estudada e corroborando achados prévios.

Nosso estudo apresentou limitações que merecem ser destacadas. Primeiramente, trata-se de um estudo retrospectivo de um banco de dados. Tal razão impede a avaliação clínica para a escolha da técnica cirúrgica adequada às abordagens da coluna cervical que permitiria uma 
melhor avaliação pré-operatória por meio da TC. Com relação à amostra, o número de indivíduos em nosso estudo não foi muito grande, mesmo sendo maior que o número de exames avaliados em estudos prévios (GUPTA et al., 2014; KAYA et al., 2011; MOLINET GUERRA; ROBLES FUENTES; ROA, 2017; TAITZ; NATHAN; ARENSBURG, 1978; ZIBIS et al., 2016). Entretanto, considerando a alta proporção de indivíduos detectados em nossa análise com variação anatômica no FT cervical, a avaliação pré-operatória dos parâmetros anatômicos do forame cervical deve ser considerada antes de realizar um procedimento cirúrgico que envolva a abordagem das vértebras cervicais. 
CONCLUSÃO 


\section{CONCLUSÃO}

Determinamos as características anatômicas e morfométricas dos forames transversos das vértebras de C3 a C7 com o uso de imagens de tomografia computadorizada em uma amostra da população brasileira e a técnica empregada apresentou elevada confiabilidade entre os observadores.

Nossos resultados foram similares aos apresentados previamente na literatura, entretanto identificamos um aumento na área do forame com o aumento da faixa etária. 


\section{REFERÊNCIAS}

AL-HABIB, A. et al. Quantitative assessment of vertebral artery anatomy in relation to cervical pedicles: surgical considerations based on regional differences. Neurosciences, Riyadh, v. 23, n. 2, p. 104-110, Apr. 2018.

ANDERSON, P. A. et al. Posterior cervical arthrodesis with AO reconstruction plates and bone graft. Spine, Hagerstown, v. 16, n. 3 Suppl, p. S72-9, Mar. 1991.

BIBLE, J. et al. Avoiding and managing intraoperative complications during cervical spine surgery. Instructional course lectures, St. Louis, v. 65, p. 281-90, 2016.

BREWIN, J.; HILL, M.; ELLIS, H. The prevalence of cervical ribs in a London population. Clinical Anatomy, New york, v. 22, n. 3, p. 331-336, 2009.

BRUNEAU, M. et al. Anatomical variations of the V2 segment of the vertebral artery. Neurosurgery, Baltimore, v. 59, n. 1 SUPPL. 1, p. 20-24, 2006.

BURKE, J. P.; GERSZTEN, P. C.; WELCH, W. C. Iatrogenic vertebral artery injury during anterior cervical spine surgery. The Spine Journal, New York, v. 5, n. 5, p. 508-514, Set. 2005.

CAGNIE, B. et al. Extrinsic risk factors for compromised blood flow in the vertebral artery: Anatomical observations of the transverse foramina from C3 to C7. Surgical and Radiologic Anatomy, Berlin, v. 27, n. 4, p. 312-316, 2005.

CHANDAK, S.; KUMAR, A. Usefulness of 3D CT in diagnosis of cervical rib presenting as supraclavicular swelling of short duration. Journal of Clinical and Diagnostic Research, India, v. 8, n. 5, p. RD01-2, May 2014.

CHOI, Y.; CHUNG, S. B.; KIM, M. S. Prevalence and anatomy of anomalous left vertebral artery originated from aorta evaluated by computed tomographic angiography. Surgical and Radiologic Anatomy, Jung-gu, v. 40, n. 7, p. 799-806, 2018.

CURYLO, L. J. et al. Tortuous course of the vertebral artery and anterior cervical decompression: A cadaveric and clinical case study. Spine, Hagerstown, v. 25, n. 22, p. 2860 2864, 2000.

DEĞIRMENCI, B.; YILMAZ, Ö. Variations of transverse foramens of cervical vertebrae: A 3 dimensional multidetector CT study. Turkish Journal of Medical Sciences, Ankara, v. 43, n. 5, p. 711-717, 2013.

ESKANDER, M. S. et al. Vertebral artery anatomy: a review of two hundred fifty magnetic resonance imaging scans. Spine, Hagerstown, v. 35, n. 23, p. 2035-40, Nov. 2010.

EVANGELOPOULOS, D. Computerized tomographic morphometric analysis of the cervical spine. The Open Orthopaedics Journal, Hilversum, v. 6, n. i, p. 250-254, 2012. 
FITZGERALD, R. T.; BARTYNSKI, W. S.; COLLINS, H. R. Vertebral artery position in the setting of cervical degenerative disease: implications for selective cervical transforaminal epidural injections. Interventional neuroradiology: journal of peritherapeutic neuroradiology, surgical procedures and related neurosciences, Milan, v. 19, n. 4, p. 425, 2013.

FLEISS, J. L.; COHEN, J. The equivalence of weighted kappa and the intraclass correlation coefficient as measures of reliability. Educational and Psychological Measurement, Chicago, v. 33, n. 3, p. 613-619, Oct. 1973.

GUAN, Q. et al. Iatrogenic vertebral artery injury during anterior cervical spine surgery: a systematic review. World Neurosurgery, New York, v. 106, p. 715-722, Oct. 2017.

GUPTA, R. et al. Variations in morphometry of foramina transversaria and vertebral artery in subaxial cervical region and its surgical implications. International J. of Healthcare and Biomedical Research. [s.l: s.n.]. Disponível em: 〈www.ijhbr.com>. Acesso em: 3 dez. 2018.

HERKOWITZ, H. N. et al. Rothman-Simeone The spine. 5th ed. Philadelphia, PA: Kim Murphy, 2006.

IONETE, C.; OMOJOLA, M. F. MR angiographic demonstration of bilateral duplication of the extracranial vertebral artery: unusual course and review of the literature. American journal of neuroradiology, Baltimore, v. 27, n. 6, p. 1304-6, 2006.

JAÉN E., M. T. Variedades anatomicas en vertebras de la colección. Anales del Instituto Nacional de Antropologia y Historia, Tlatelolco, Época 7, Tomo IV, v. 52, p. 71-81. Disponível em: $<$ https://biblioteca.ufm.edu/library/index.php?title=Special:GSMSearchPage\&process\&autor =JAEN E., MARIA TERESA >. Acesso em: 4 dez. 2018.

JEANNERET, B. et al. Posterior stabilization of the cervical spine with hook plates. Spine, Hagerstown, v. 16, n. 3 Suppl, p. S56-63, 1991.

KAJIMOTO, B. H. J. et al. Estudo anatômico do trajeto da artéria vertebral na coluna cervical inferior humana. Acta Ortopédica Brasileira, São Paulo, v. 15, n. 2, p. 84-86, 2007.

KAYA, S. et al. Double foramen transversarium variation in ancient Byzantine cervical vertebrae: preliminary report of an anthropological study. Turkish neurosurgery, Ankara, v. 21, n. 4, p. 534-8, 2011.

KIM, C. et al. A quantitative comparison of the vertebral artery and transverse foramen using CT angiography. Journal of clinical neurology (Seoul, Korea), Seoul, v. 8, n. 4, p. 259-64, Dez. 2012.

KOVACS, A. Subluxation and deformation of the cervical apophyseal joints; a contribution to the aetiology of headache. Acta radiologica, Stockholm, v. 43, n. 1, p. 1-16, jan. 1955.

LESTINI, W. F.; WIESEL, S. W. The pathogenesis of cervical spondylosis. Clinical orthopaedics and related research, Philadelphia, n. 239, p. 69-93, fev. 1989. 
LO, W. B.; NAGARAJA, S.; SAXENA, A. Delayed hemorrhage from an iatrogenic vertebral artery injury during anterior cervical discectomy and successful endovascular treatmentreport of a rare case and literature review. World Neurosurgery, New York, v. 99, p. 811.e11811.e18, mar. 2017.

MAGRO, E. et al. Contribution of embryology in the understanding of cervical venous system anatomy within and around the transverse foramen: A review of the classical literature. Surgical and Radiologic Anatomy, Berlin, v. 36, n. 5, p. 411-418, 2014.

MALLA, H. P. et al. Study of the transverse foramen in the subaxial cervical spine in korean patients with degenerative changes: an anatomical note. Neurospine, Seoul, v. 15, n. 2, p. $163-$ $168,2018$.

MEILA, D. et al. Origin and course of the extracranial vertebral artery: cta findings and embryologic considerations. Clinical Neuroradiology, Munich, v. 22, n. 4, p. 327-333, Dez. 2012.

METIN TELLIOGLU, A. et al. Evaluation of morphologic and morphometric characteristic of foramen transversarium on 3-dimensional multidetector computed tomography angiography. Turkish Neurosurgery, Ankara, v. 28, n. 4, p. 557-562, 2018.

MIKKELSEN, W. M.; DUFF, I. F.; DODGE, H. J. Age-sex specific prevalence of radiographic abnormalities of the joints of the hands, wrists and cervical spine of adult residents of the Tecumseh, Michigan, Community Health Study area, 1962-1965. Journal of Chronic Diseases, St. Louis, v. 23, n. 3, p. 151-159, 1970.

MOLINET GUERRA, M.; ROBLES FUENTES, P.; ROA, I. Anatomical variations of the foramen transversarium in cervical vertebrae. International Journal of Morphology, Temuco, v. 35, n. 2, p. 719-722, 2017.

NEO, M. et al. Vertebral artery injury during cervical spine surgery: a survey of more than 5600 operations. Spine, Hagerstown, v. 33, n. 7, p. 779-85, 1 abr. 2008.

OKUYAMA, K. et al. Vertebral pedicle diameter as determined by computed tomography: inaccuracies observed by direct measurement of cadaveric lumbar spine. Skeletal radiology, Berlin, v. 23, n. 7, p. 551-3, out. 1994.

PANJABI, M. M. et al. Internal morphology of human cervical pedicles. Spine, Hagerstown, v. 25, n. 10, p. 1197-205, 15 maio 2000.

Philips - Brilliance CT Big Bore Radiology CT scanner. Disponível em: $<$ https://www.philips.com.br/healthcare/product/HCNCTB606/brilliance-ct-big-bore radiology-ct-scanner>. Acesso em: 17 dez. 2018.

PUTZ, R.; PABST, R. Atlas de anatomia humana Sobotta. 21. ed. Rio de Janeiro: Guanabara Koogan, 2000.

ROY-CAMILLE, R. et al. Treatment of lower cervical spinal injuries--C3 to C7. Spine, Hagerstown, v. 17, n. 10 Suppl, p. S442-6, out. 1992. 
SCANLON, G. C. et al. Cervical transforaminal epidural steroid injections. Spine, Hagerstown, v. 32, n. 11, p. 1249-1256, 15 maio 2007.

SCHALL, R. Estimation in generalized linear models with random effects. Biometrika, London, v. 78, n. 4, p. 719-727, 1 dez. 1991.

SIM, E. et al. Fenestration of the extracranial vertebral artery: review of the literature. Spine, Hagerstown, v. 26, n. 6, p. E139-42, 2001.

STEINER, H. A. Roentgenologic manifestations and clinical symptoms of rib abnormalities. Radiology, v. 40, n. 2, p. 175-178, 1943.

SUREKA, B. et al. Morphometric analysis of cervical spinal canal diameter, transverse foramen, and pedicle width using computed tomography in Indian population. Neurology India, Bombay, v. 66, n. 2, p. 454, 2018.

TAITZ, C.; NATHAN, H.; ARENSBURG, B. Anatomical observations of the foramina transversaria. Journal of Neurology Neurosurgery and Psychiatry, London, v. 41, n. 2, p. 170-176, 1978.

THOMPSON, J. C. Atlas de Anatomia Ortopédica de Netter. Porto Alegre: ARTMED, 2004.

Vernier caliper -- Britannica Academic. Disponível em: <https://academic-ebbritannica.ez67.periodicos.capes.gov.br/levels/collegiate/article/vernier-caliper/75132>. Acesso em: 12 dez. 2018.

ZHAO, L. et al. Quantitative evaluation of the location of the vertebral artery in relation to the transverse foramen in the lower cervical spine. Spine, Hagerstown, v. 33, n. 4, p. 373-8, 2008.

ZIBIS, A. et al. Variations of transverse foramina in cervical vertebrae: what happens to the vertebral artery? European Spine Journal, Heidelberg, v. 27, n. 6, p. 1278-1285, 2018.

ZIBIS, A. H. et al. Anatomical variations of the foramen transversarium in cervical vertebrae: findings, review of the literature, and clinical significance during cervical spine surgery. European Spine Journal, Heidelberg, v. 25, n. 12, p. 4132-4139, 2016. 
ANEXO A 


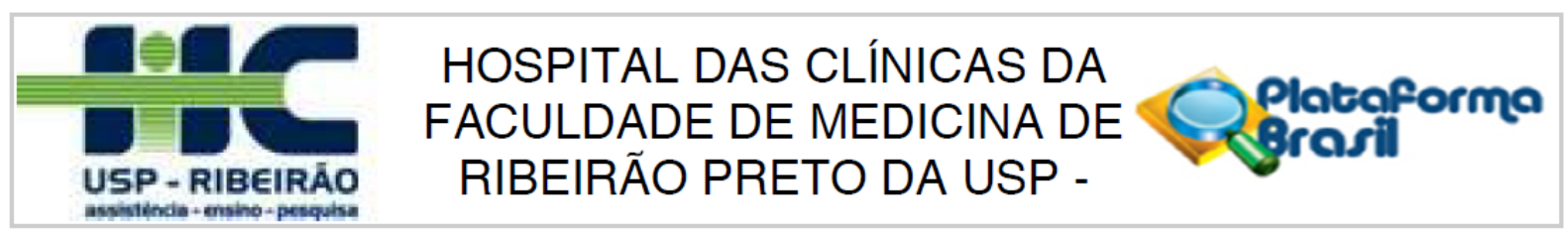

\section{PARECER CONSUBSTANCIADO DO CEP}

\section{DADOS DO PROJETO DE PESQUISA}

Título da Pesquisa: Estudo morfométrico do forame transverso

Pesquisador: Carlos Fernando Pereira da Silva Herrero

Área Temática:

Versão: 1

CAAE: 46635615.0 .0000 .5440

Instituição Proponente: Hospital das Clínicas da Faculdade de Medicina de Ribeirão Preto da USP -

Patrocinador Principal: Financiamento Próprio

\section{DADOS DO PARECER}

Número do Parecer: 1.153 .786

Data da Relatoria: 29/06/2015

\section{Apresentação do Projeto:}

Projeto: introdução redigida de forma simples e objetiva. Ressalta a importância do conhecimento das alteraçōes e variações morfológicas do forame transverso das vértebras cervicais na população e tem como hipótese uma potencial diferença entre as características da população brasileira e a media mundial, no que diz respeito a variações de diâmetro, formato e anomalias congênitas outras. O desenho metodológico é simples e exequível. Prevê a análise da area, diâmetros anteroposterior, lateral e anormalidades do forame transverso das vertebras cervicais através de um software denominado OsiriX.

\section{Objetivo da Pesquisa:}

Avaliar o formato do forame transverso das vértebras cervicais na população de indivíduos atendidos na UE do HCFMRP-USP.

\section{Avaliação dos Riscos e Benefícios:}

O responsável preve como único risco a perda de confidencialidade dos dados, mas informa que esse risco será minimizado, pois apenas utilizarão as informaçōes de sexo e idade do sujeito, sem qualquer menção ou uso do registro ou nome ou quaisquer outras informações que possam permitir o reconhecimento do mesmo. Não há benefícios diretos previstos.

\section{Comentários e Considerações sobre a Pesquisa:}

A plano de trabalho tem relevância clínica, é simples e exequível. Em resumo, O conhecimento da

Endereço: CAMPUS UNIVERSITÁRIO

Bairro: MONTE ALEGRE

UF: SP Município: RIBEIRAO PRETO

Telefone: (16)3602-2228 Fax: (16)3633-1144 E-mail: cep@hcrp.usp.br 


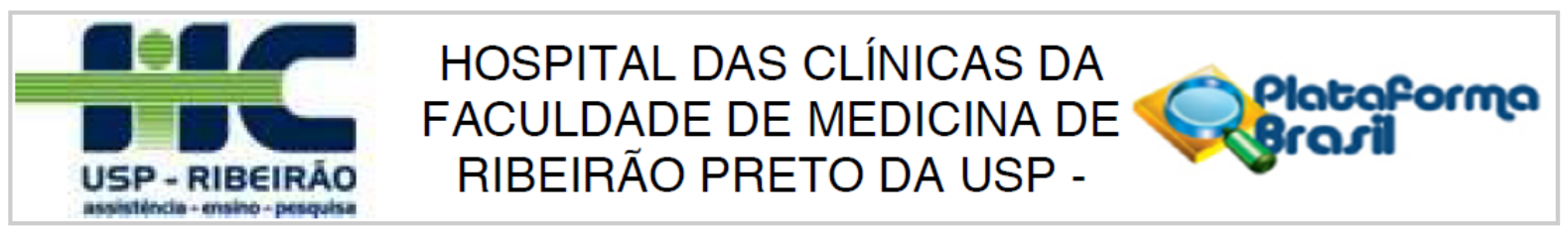

Continuaçăo do Parecer: 1.153.786

morfologia e anatomia das vértebras da coluna cervical, das estruturas adjacentes, e suas variaçōes é essencial para a realização segura de procedimentos cirúrgicos na coluna vertebral cervical. Muitos desafios existem com o desenvolvimento das técnicas cirúrgicas para a coluna cervical, incluindo a proximidade de estruturas neurovasculares, variabilidade anatômica e dificuldades radiográficas. A artéria vertebral, a veia vertebral e o plexo simpático vertebral passam através do forame transverso (FT) das vértebras cervicais. Além disso, a incidência de mal formações do forame transverso apresenta resultados variáveis na literatura atual, colocando em risco as estruturas supracitadas. Os resultados na literatura atual da morfometria das vértebras da coluna cervical não englobam a população brasileira, o que motivou a realização deste projeto.

\section{Considerações sobre os Termos de apresentação obrigatória:}

Todos os termos adequadamente preenchidos conforme a Resolução 466/12.

\section{Recomendações:}

INão se aplica.

\section{Conclusões ou Pendências e Lista de Inadequações:}

Diante do exposto e à luz da Resolução CNS 466/2012, o projeto de pesquisa, assim como a dispensa do Termo de Consentimento Livre e Esclarecido, podem ser enquadrados na categoria APROVADO.

\section{Situação do Parecer:}

Aprovado

\section{Necessita Apreciação da CONEP:}

Não

\section{Considerações Finais a critério do CEP:}

Projeto Aprovado: Tendo em vista a legislação vigente, devem ser encaminhados ao CEP, relatórios parciais anuais referentes ao andamento da pesquisa e relatório final ao término do trabalho. Qualquer modificação do projeto original deve ser apresentada a este CEP em nova versão, de forma objetiva e com justificativas, para nova apreciação.

Endereço: CAMPUS UNIVERSITÁRIO Bairro: MONTE ALEGRE

UF: SP Município: RIBEIRAO PRETO

Telefone: (16)3602-2228 Fax: (16)3633-1144 E-mail: cep@hcrp.usp.br 


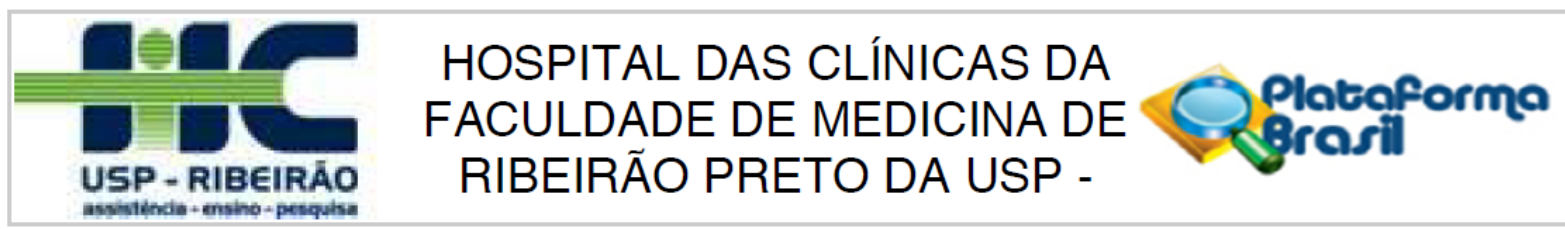

Continuaçăo do Parecer: 1.153.786

RIBEIRAO PRETO, 20 de Julho de 2015

Assinado por:

MARCIA GUIMARÃES VILLANOVA

(Coordenador)

Endereço: CAMPUS UNIVERSITÁRIO

Bairro: MONTE ALEGRE

CEP: $\quad 14.048-900$

UF: SP

Município: RIBEIRAO PRETO

Telefone: (16)3602-2228 Fax: (16)3633-1144

E-mail: cep@hcrp.usp.br

Página 03 de 03 